\title{
TOO MANY THINGS TO DO: HOW TO DEAL WITH THE DYSFUNCTIONS OF MULTIPLE-GOAL AGENCIES
}

\author{
Eric Biber*
}

\begin{abstract}
All federal agencies must cope with the challenges of trying to achieve success on the multiple goals laid out for them by Congress, the President, or the public at large. Recent economics and political science literature provides a theoretical framework that helps explain why agencies might succeed in achieving some goals and fail in achieving others: Agencies will systematically underperform on goals that are hard to measure and that conflict with the achievement of other, more measurable goals. While agencies in theory might be able to improve their ability to measure performance through technological and organizational innovation, in many cases agency missions, historical inertia, and the professional orientation of agency staff will interfere with innovation. Principals (such as Congress) have various options to address this problem. Some options focus on changing the agency itself: (1) having the principal take back decision-making authority from the agency; (2) splitting agencies into components that pursue different goals; or (3) mandating that the agency innovate in developing information about undervalued goals. All of these intra-agency efforts have their limitations: Principals only have so much time and energy to make decisions themselves; splitting agencies is often not feasible; and agencies may be resistant to external cultural change. Another range of options involves having another agency monitor the decision-making agency to ensure minimal compliance with performance on one or more goals. This could include having one agency comment on the decision-making agency's performance on an undervalued goal (the "agency as lobbyist" model) or could extend to having another agency make legally binding determinations about whether the decision-making agency has met minimum standards for that undervalued goal (the "agency as regulator" model). The more stringent the inter-agency monitoring is, the more effective regulation might be at achieving minimum compliance with undervalued goals, but with the consequence of greatly increasing transaction costs such as litigation. Thus, principals will not only have to trade off agency performance among multiple goals, but will also have to trade off among the various solutions they might try to use to address the problems of multiple-goal agencies.
\end{abstract}

\section{TABLE of Contents}

I. Introduction .................................. 2

II. The Dilemma of Multiple-Goal Agencies................ 6

A. The Ubiquity of Multiple-Goal Agencies ............. 7

B. The Logic of Multiple-Goal Agencies.............. 9

* Acting Professor of Law, University of California, Berkeley, Boalt Hall School of Law. I am grateful for comments from Dan Farber, Goodwin Liu, Erin Murphy, Anne Joseph O'Connell, Molly van Houweling, Ken Bamberger, KT Albiston, Melissa Murray, Robert Kagan, Jacob Gersen, Matthew Stephenson, Heather Elliott, Tino Cuellar, Jonathan Masur, Kristin Hickman, David Zaring, Cristina Rodriguez, Dan Ho, Nathan Sayre, Sally Fairfax, Tim Duane, Lisa Blomgren Bingham, Patrick Hanlon, Fred Cheever, John Yoo, Andrew Guzman, Holly Doremus, Bruce Ackerman, Tom Merrill, Ricky Revesz, Joe Sax, and the participants in the 2008 Yale/Stanford Junior Faculty Forum. Special thanks to Patricia Kuo, Daniel Pollak, Jason Malinsky, and Jay Cha-Young Kim for research assistance. Thanks to Doug Avila at the Berkeley Law School Library for invaluable help in collecting sources. All remaining errors and omissions are, of course, my own. 
C. Can Agencies Solve the Problem Themselves? ..........

1. Limits on the Ability of Agencies to Solve the Problem Themselves ................................

2. Evidence of the Inability of Agencies to Solve the Problem Themselves: A Case Study of the U.S. Forest Service ................................. 17

D. Is There a Problem? ......................... 30

III. "Intra-Agency" Solutions: Reclaiming Power, Separating

Functions and Changing Internal Agency Cultures ...........

A. Reclaiming Power: Principal Retaking Important Decisions that Involve Fundamental Tradeoffs

B. Separating Functions: The Difficulty of Separating Interconnected and Interrelated Goals...............

C. Changing Internal Agency Cultures: Resistance to Change and the Inevitable Necessity of a Primary Goal .........

IV. Using Inter-Agency Interactions to Solve the Dilemma of Multiple-Goal Agencies .............................

A. The Model of "Agency as Lobbyist"..................

$B$. The Model of "Agency as Regulator" .................

1. Direct Regulation: The Office of Management and

Budget and Cost-Benefit Analysis ................

2. Indirect Regulation: The Endangered Species Act ....

3. The Advantages and Disadvantages of Inter-Agency

Regulation ............................ 57

C. The Continuum from Lobbyist to Regulator ........... 59

V. Conclusion: A Range of Solutions with Their Own Tradeoffs.. 60

Figure 1: Typology of Options to Address Multiple-Goal Problems . 62

Figure 2: Advantages and Disadvantages of Options to Address the

Problems of Multiple-Goal Agencies .....................

\section{INTRODUCTION}

Of all the federal administrative agencies, federal public land management agencies have perhaps the most diverse and sweeping range of goals that they are required to accommodate. Agencies such as the Bureau of Land Management ("BLM") and the U.S. Forest Service are required to fulfill the goals of "multiple-use" management, which includes managing their lands to maximize domestic mineral and oil production; provide for livestock grazing and timber production; allow for motorized and non-motorized recreational use; encourage local economic and infrastructure development; protect soil, air, and water quality; conserve wildlife populations; recover endangered species; and set aside certain lands as wilderness. ${ }^{\dagger}$

' See, e.g., Multiple-Use Sustained-Yield Act (MUSYA) of 1960, 16 U.S.C. $§ 528$ (2000) (laying out the management goals for the Forest Service: "[i]t is the policy of the Congress that the national forests are established and shall be administered for outdoor recreation, range, 
Given this exotic menagerie of management goals and duties, it is no surprise that federal public land management has long been extremely contentious, both in the political and legal arenas. ${ }^{2}$

Public land management agencies are no more than an extreme example of a problem that all federal agencies face - deciding how to trade off between two or more goals that the agency is charged by Congress to achieve. Indeed, in this way government agencies are no different from people themselves, who generally have a range of interests and purposes that motivate their life: raising a family, succeeding in their careers, and pursuing hobbies and sports.

More than occasionally, those different goals will conflict. A person, for example, may be forced to choose between staying in the office all weekend to meet an urgent deadline, or attending his or her child's sixth birthday party. Likewise, a land management agency such as the National Park Service will be faced with the inevitable conflict between protecting a place such as the Yosemite Valley from the harms of air pollution, and providing access to millions of visitors a year who wish to drive to the Valley to experience its wonders.

Given these conflicts, it is perhaps inevitable that to some extent one goal will consistently supersede others. A workaholic, for instance, will regularly choose to complete additional work tasks over attending a child's soccer game or birthday party. Likewise, federal public land management agencies have been accused of systematically privileging one or more of their goals - often related to economic development - over others often related to environmental protection. ${ }^{3}$

For people, the solution might be a session with a therapist. For agencies, however, the solution may lie at least in part in the realm of institutional and organizational design. Recent economics, political science, and legal literature has explored aspects of the problem of the multiple-goal agency, and how that problem might be solved. This Article takes the aspects of the problem and the solutions already developed in the literature and pieces them together into a theoretical framework that lays out the range of

timber, watershed, and wildlife and fish purposes"); Federal Land Policy and Management Act (FLPMA) of 1976, 43 U.S.C. $\$ 1701$ (a)(8) (2000) (laying out congressional policy that public lands be managed by BLM to "protect the quality of scientific, scenic, historical, ecological, environmental, air and atmospheric, water resource, and archeological values; . . preserve and protect certain public lands in their natural condition; . . provide food and habitat for fish and wildlife and domestic animals; and ... provide for outdoor recreation and human occupancy and use").

2 See generally Steven Lewis Yaffee, The Wisdom of the Spotted Owl: Policy LesSONS FOR A NEW CENTURY (1994) (providing history of decades-long legal and political fight over management of old-growth forests in national forests in Pacific Northwest, culminating in a presidentially convened stakeholder summit).

${ }^{3} \mathrm{~A}$ powerful example of such privileging is the prioritization of timber production that some observers have attributed to the Forest Service. See infra notes 54-109 and accompanying text. 
options that institutional and legal designers can rely upon to address the problems of multiple-goal agencies.

The Article begins by providing a quick analysis of the situations in which agencies are most likely to shirk their duty to fulfill various tasks that they have been given. Drawing on recent models and studies, the Article concludes that agencies are most likely to underperform on "secondary goals" that both interfere with the completion of what are perceived to be the agency's primary goals, and are not easily measured or monitored by outside parties. While agencies may seek to solve this problem on their own, in many cases a range of institutional incentives and other constraints will limit the ability of agencies to balance their competing objectives on their own - in particular historical inertia and the need for agencies to recruit and maintain a dedicated and committed group of employees. Moreover, the challenge of balancing among multiple goals may result in agency performance diverging from the instructions of the principal, ${ }^{4}$ even if other problems that have been explored in the literature - such as agency slack or capture of agencies by special interests - do not exist.

As this Article will show, performance across multiple goals is a pervasive problem for institutional and legal design in the administrative state. And while it is a topic that may not have received much attention in the academic literature, real-world politicians and bureaucrats must address it on a regular basis. It is accordingly no surprise that a wide range of legal and institutional design choices can be seen as efforts to solve the problem of the multiple-goal agency. This Article takes those legal and institutional design choices, shows how they try to solve the problem of balancing multiple goals, and develops a theoretical structure for understanding how they might succeed or fail.

There are two separate ways one can categorize efforts to resolve the problems of multiple-goal agencies. One typology focuses on institutional structure, and it distinguishes between whether the solution seeks to directly change the structure of the agency (what this Article calls "intra-agency" solutions) or instead tries to use the interaction among multiple agencies to provide a check on the tendency of agencies to overemphasize certain goals (what this Article calls "inter-agency interaction"). The other typology focuses on how the solution affects the functioning of the agency, and depends on which part of the multiple-goal agency problem the solution seeks to address - splitting up goals among agencies in order to eliminate potential conflicts among multiple goals ("goal splitting" solutions) or reducing intraagency obstacles to developing innovative solutions for measuring secondary goals ("innovation" solutions). "Intra-agency" institutional structure

\footnotetext{
${ }^{4} \mathrm{~A}$ principal is a party that delegates performance of a task to an agent, usually because the principal is limited in its ability to perform the task directly by time, expertise, or other resources. As discussed infra at notes 24 and 54, generally speaking this Article considers the primary principal to be Congress and the agent to be a federal administrative agency, and limits the discussion to one principal and one agent to make analysis feasible.
} 
solutions may either focus on splitting goals or on improving innovation, as may "inter-agency interaction" solutions. And some solutions may be hybrids that bridge these categories. Figure 1 provides an overview of these typologies.

There are patterns to the strengths and weaknesses of the various legal and institutional design strategies as well. Some are much more aggressive in attempting to change agency missions to increase innovation in measurement of goals and accordingly may be more successful in forcing change, but these efforts will generally require increased monitoring and enforcement efforts by the principal, undermining the benefits of delegation. Others may not require direct enforcement by the principal, but instead may have high transaction costs because of the need for enforcement by non-governmental parties, or may simply not be feasible.

The section of this Article that explores solutions is organized by the institutional structure typology. First, it examines "intra-agency" solutions - efforts by principals, such as Congress or the President, to solve the problem of agencies balancing multiple goals by directly changing the structure of functioning of the agency itself. Second, it examines "inter-agency interaction" solutions - efforts by the principals to solve the problem by using other agencies to monitor or regulate performance of the decision-making agency.

Within the "intra-agency" solutions category, three main alternatives have developed. First, principals might take back decision-making authority for themselves, eliminating the delegation to the agent. Second, they might separate the various conflicting tasks into different agencies, each with its own exclusive tasks or goals. Finally, principals might attempt to change the mission of an agency so that it is more likely to develop innovative methods of measuring performance on the full range of its goals.

Instead of trying to alter the agency structure directly, a principal might try to use other agencies to change the dynamic of the decision-making agency's process. The advantage here is that the monitoring agency may have a mission different from the decision-making agency - a mission that may be much more sympathetic to the development of innovative ways of measuring performance on the full range of goals. That improved information can either help the principal to better evaluate performance of the decision-making agency, or produce pressure on the decision-making agency to improve its own measurements of performance on secondary goals.

One model, identified by Professors DeShazo and Freeman, involves agencies acting as "lobbyists," participating in each others' decision-making processes in order to ensure that certain values or goals are not systematically ignored. ${ }^{5}$ Here, a monitoring agency's comments on another agency's decision have little or no legal consequences for the decision-making agency

${ }^{5}$ J.R. DeShazo \& Jody Freeman, Public Agencies as Lobbyists, 105 Colum. L. Rev. 2217 (2005). 
- the impact of the comments will be based primarily on their persuasiveness or political import, and on the pressure they may place on the decisionmaking agency to develop better measures of performance on secondary goals. This model may be less likely to force a change in the mission orientation of the decision-making agency, but it also requires less involvement or enforcement by the principal.

On the other end of the spectrum is an agency that is able to block another agency's decisions, an "agency as regulator" of another agency. In this approach, the pressure on the decision-making agency is much greater, and it may be more likely to force it to develop innovative ways of measuring performance on the secondary goals. Two examples of this model are review of agency regulations for economic efficiency by the Office of Management and Budget ("OMB"), and federal agency consultation with the U.S. Fish and Wildlife Service ("FWS") pursuant to the Endangered Species Act ("ESA") ${ }^{6}$ to ensure that agency actions do not cause endangered species to go extinct. Enforcement of the monitoring agency's decisions may either be made directly by the principal (as with OMB, whose decisions are enforced by the President), or indirectly by the possibility of legal action by a wide range of non-governmental actors separate from the principal (as with FWS consultation under the ESA, which is enforceable by a citizen suit provision). Both of these regulatory models may be much more effective than the lobbyist model, but each has greater costs as well. Direct enforcement in the mode of OMB review can require significant time and energy from the principal, again cutting into the benefits of delegation. Indirect enforcement in the mode of the ESA can result in significant transaction and litigation costs that might overwhelm the benefits of the review process.

Part I of this Article lays out the theoretical model of multiple-goal agencies, describes how and why they may choose to systematically privilege some goals over others, and, using the Forest Service as a case study, examines why agencies will often be unsuccessful in attempting to address this problem. Part II then explores the "intra-agency" institutional structure solutions, while Part III develops the overall framework of "inter-agency interaction," extending from the "agency as lobbyist" to the "agency as regulator."

\section{The Dilemma of Multiple-Goal Agencies}

This Article begins by demonstrating that the problem of the multiplegoal agency is ever-present in the federal government. The discussion then turns to a survey of the economics and political science literature that has examined the problems that face principals who have tasked agents with multiple goals. Because federal agencies can be seen as agents, tasked with

\footnotetext{
${ }^{6}$ Endangered Species Act of 1973, Pub. L. No. 93-205, 87 Stat. 884 (codified as amended in scattered sections of 16 U.S.C.).
} 
goals by one or more principals (Congress, the President, the public), this literature can be extremely helpful for understanding how those agencies function and what their dysfunctions might be. One primary insight is that agents will have systematic incentives to privilege certain goals over others - specifically, to privilege goals that are easily measured over conflicting goals that are difficult to measure. This Article then explores whether agencies may or may not be able to address these problems through their own efforts to improve assessment of difficult-to-measure goals. Through examination of the history of the Forest Service, as well as other examples, this Article establishes that due to a range of constraints, including internal institutional incentives that are often crucial to the success of government agencies, those agencies often will not be able to overcome the challenges posed by conflicting multiple goals on their own.

\section{A. The Ubiquity of Multiple-Goal Agencies}

The Forest Service and BLM, the public land agencies mentioned in the Introduction, are only two of many examples of agencies in the federal government that have multiple conflicting goals. Other federal land management agencies are similarly faced with conflicting goals: The National Park Service is required both to protect the natural resources of the parks and to develop facilities for visitors; ${ }^{7}$ and FWS is required both to manage wildlife refuges for the conservation of plants and animals and to provide for recreation on those refuges. ${ }^{8}$

Nor are these dilemmas restricted to the management of natural resources. They are indeed found throughout the federal government. The Food and Drug Administration ("FDA"), for instance, is charged both with ensuring that new drugs placed on the market are safe and effective (a task that generally requires cautious and deliberate action) and with speedily granting access for doctors and patients to those new, safe, and effective drugs (a task that requires expeditious review of those drugs). ${ }^{9}$ The Federal Aviation Administration ("FAA") is tasked with both developing and ex-

${ }^{7}$ See 16 U.S.C. $\$ 1$ (2000) (giving the Park Service a mandate to "conserve the scenery and the natural and historic objects and the wild life therein and to provide for the enjoyment of the same in such manner and by such means as will leave them unimpaired for the enjoyment of future generations").

${ }^{8}$ See id. $\S 668 \mathrm{dd}(\mathrm{a})(2)-(3)(\mathrm{B})$ (mandating that National Wildlife Refuge System, managed by FWS, is "for the conservation, management, and where appropriate, restoration of . . fish, wildlife, and plant resources" but also includes "compatible wildlife-dependent recreation").

${ }^{9}$ Compare 21 U.S.C. \$393(b)(1) (2000) (defining mission of FDA, including "promot[ing] the public health by promptly and efficiently reviewing clinical research and taking appropriate action on the marketing of regulated products in a timely manner"), with id. $\S 393$ (b)(2) ("[W]ith respect to such products, [the FDA shall] protect the public health by ensuring that ... human ... drugs are safe and effective ...."). See also, e.g., Gardiner Harris, Potentially Incompatible Goals at FDA, N.Y. TIMEs, June 11, 2007, at A14 (laying out this tradeoff). 
panding our air transportation network to provide for economic growth and ensuring that that network is safe. ${ }^{10}$

All of these multiple goals obviously require a balancing act, particularly since many of them may directly conflict. How quickly can we expedite approval of drugs to ensure that patients receive the benefits of novel therapies, at the possible expense of failing to screen out those drugs that are not, in fact, safe or effective? How much and how quickly can our air transportation system expand without inappropriately risking safety? How much mining and grazing should BLM allow on its lands while still allowing for wildlife or fish conservation and outdoor recreation?

Of course, in some cases Congress provides a prioritization among the various goals. For the Park Service and FWS, for example, Congress appears to have made clear that the agencies are to prioritize conservation of natural resources over the provision of facilities for the recreation of visitors. ${ }^{11}$ But even in these cases, the agency is still left with the question of how much to pursue the secondary goal, given the possibility of direct conflict among those goals. How much development for tourism is too much, such that it interferes with conservation of natural resources in the national parks? At what level is the development of recreation no longer "compatible" with the conservation of wildlife and plants on wildlife refuges?

Indeed, the problem of multiple goals is even more difficult than these questions suggest. Congress has not limited the imposition of multiple goals to organic acts that establish single agencies with multiple goals. Congress has also imposed goals on all agencies in the federal government, which may complement or conflict with the primary goals the agencies face. The classic example of this is the National Environmental Policy Act ("NEPA"), which requires "all federal agencies" to take into consideration the environmental impacts of their actions and where possible minimize those impacts. ${ }^{12}$ Following the precedent set by NEPA, Congress has enacted a mini-universe of other across-the-board responsibilities with which all federal agencies must comply, including paperwork reduction,,$^{13}$ freedom of information, ${ }^{14}$

${ }^{10}$ See 49 U.S.C. $\$ 40104$ (a) (2000) ("The Administrator of the [FAA] shall encourage the development of civil aeronautics and safety of air commerce in and outside the United States.").

"See 16 U.S.C. $\S 1$ (stating that the Park Service is to "provide for the enjoyment of" natural resources by park visitors "in such manner and by such means as will leave" natural resources "unimpaired"); id. $\S \S 668 \mathrm{dd}(\mathrm{a})(3)(\mathrm{B}), 668 \mathrm{ee}(1)$ (stating that only "compatible" recreation is permitted in national wildlife refuges, which is defined as recreation that "in the sound professional judgment of the [FWS] Director, will not materially interfere with or detract from the fulfillment of the mission of the System or the purposes of the refuge").

${ }^{12}$ See 42 U.S.C. $\$ 4332$ (B) (2000) (requiring all federal agencies to "insure that presently unquantified environmental amenities and values may be given appropriate consideration in decisionmaking along with economic and technical considerations"); id. $\S 4332$ (C) (requiring federal agencies to develop environmental impact statements for all major federal actions).

${ }^{13}$ See Paperwork Reduction Act, 44 U.S.C. $\$ 3501$ (2000) (describing congressional intent to "minimize the paperwork burden ... resulting from the collection of information by or for the Federal government"); id. $\$ 3506$ (requiring all federal agencies to comply with paperwork reduction goals and regulations). 
minimization of impacts on small businesses, ${ }^{15}$ and elimination of racial discrimination in federally funded programs. ${ }^{16}$

Thus, in some way, every federal agency is confronted with the challenge of achieving multiple goals. ${ }^{17}$ Congress, the President, and indeed the general public, in turn, are faced with the challenge of ensuring that the federal agencies achieve those multiple goals, while at the same time balancing them "properly." And, of course, as even the few brief examples given above indicate, conflicts will inevitably arise in achieving those many goals.

\section{B. The Logic of Multiple-Goal Agencies}

Government agencies that have one or more tasks to perform were given those tasks by the legislature, the chief executive, or some other political body. They accordingly can be seen as "agents" attempting to fulfill the goals laid out by "principals" such as Congress, the President, or the public as a whole. Economists and political scientists have developed an extensive literature examining the problems of principal-agent interactions, with specific applications for governmental and non-profit organizations. That literature provides us with some important insights into the nature and logic of how agencies tasked with multiple goals are likely to function. In particular, it predicts that agencies faced with conflicting tasks will systematically overperform on the tasks that are easier to measure and have higher incentives, and underperform on the tasks that are harder to measure and have lower incentives. Indeed, this distortion is a fundamental problem in government, one that will exist even if the more commonly studied challenges to public administration - e.g., agency slack, agency capture, or conflicts among multiple principals - are not present.

Principal-agent analysis considers a nearly uniform situation in human affairs - the delegation of tasks from one individual or organization (the principal) to another (the agent). ${ }^{18}$ The principal has certain goals that she wishes to see achieved, but it would be more efficient for the principal to pay an agent to actually implement those goals. The most obvious example of this type of relationship is that of an employer and employee in a private business. Accordingly, principal-agent analysis has long been a sub-field of economics that has provided important and useful insights for understanding

${ }^{14}$ See Freedom of Information Act, 5 U.S.C. $\$ 552$ (2000) (requiring agencies to make specified information available to public).

${ }^{15}$ See 5 U.S.C. $\$ \S 603-604$ (2000) (requiring agencies to prepare statements about impacts that certain regulatory activities might have on small businesses and to explain how agencies have minimized those impacts).

${ }^{16}$ See 42 U.S.C. $\S 2000$ d-1 (2000) (requiring all federal agencies that provide grants or other financial assistance to end racial discrimination in funded programs).

17 See James Q. Wilson, Bureaucracy: What Government Agencies Do and Why THEY Do IT 129-31 (1989) (noting ubiquity of "contextual goals," i.e., secondary goals, for all government agencies).

${ }^{18}$ See Avinash Dixit, Incentives and Organizations in the Public Sector: An Interpretative Review, 4 J. Hum. Resources 696, 697 (2002). 
the structure of private, profit-seeking firms - helping explain why firms would diversify or consolidate products, why firms would allocate tasks within different divisions in different ways, and why firms would provide incentives of varying levels for success on various tasks.

The basic problems of any principal-agent system are those of differing incentives and inadequate information. Agents will almost always have different incentives from their principals. Moreover, it will cost the principal (whether in terms of effort or money) to attempt to gather information about the agent's activities to determine to what extent the agent is actually pursuing the principal's goals. Economists have found that these two problems can interact in a variety of ways to undermine the principal's efforts to achieve its goals through a principal-agent relationship, and in turn have explored the various organizational solutions that firms might wish to use to overcome these obstacles. ${ }^{19}$

The simplest situation, of course, is one where there is one principal, one agent, and the principal only has one goal to achieve (for instance, maximize production of the quantity of a widget). However, such a situation is rarely reflective of reality in even the simplest industry. Accordingly, economic theory has been extended to cover situations where there are multiple principals, ${ }^{20}$ multiple agents, ${ }^{21}$ multiple goals, ${ }^{22}$ and often some combination of these additional complexities.

As noted above, government agencies can also be seen as agents in a principal-agent relationship, and both economists and political scientists have accordingly drawn upon the economics literature to generate positive and normative conclusions about organizational design in the public sector. ${ }^{23}$ For purposes of this Article, these efforts of economists and political scientists are interesting because they provide some important predictions about how agencies tasked with multiple goals by a principal are likely to behave. ${ }^{24}$

${ }^{19}$ See id. at 697-701 for an overview.

${ }^{20}$ See, e.g., id. at 709-10, 711-12; Carol Propper \& Deborah Wilson, The Use and Usefulness of Performance Measures in the Public Sector, 19 Oxford Rev. ECON. Pol'Y 250, 25152 (2003).

${ }^{21}$ See, e.g., Dixit, supra note 18, at 707-08; Bengt Holmström \& Paul Milgrom, Regulating Trade Among Agents, 146 J. Instrtutional \& Theoretical Econ. 85 (1990); Ram T. S. Ramakrishnan \& Anjan V. Thakor, Cooperation Versus Competition in Agency, 7 J.L. Econ. \& ORG. 248 (1991); Hal R. Varian, Monitoring Agents with Other Agents, 146 J. InstituTIONAL \& ThEORETICAL ECon. 153 (1990); Birger Wernerfelt, Comment, Monitoring Agents with Other Agents, 146 J. Instrrutional \& ThEORETICAL ECON. 177 (1990).

${ }^{22}$ See, e.g., Dixit, supra note 18, at 704-07.

${ }^{23}$ See, e.g., id. at 696.

${ }^{24}$ Of course, many government agencies face not only multiple goals, but also serve multiple principals. While the problems raised by the existence of multiple principals are important and interesting, they are left outside the scope of this Article in order to keep the analysis manageable at this preliminary stage. See Michael M. Ting, A Theory of Jurisdictional Assignments in Bureaucracies, 46 AM. J. Pol. ScI. 364, 365 n.4 (2002) (analyzing the most efficient way to allocate multiple goals across multiple agencies, but limiting the analysis to the singleprincipal context for the initial stage of analysis). Unlike this Article, Ting looks solely at the 
The first insight is based on the interaction between the various tasks given to an agent - are those tasks complements or substitutes? Complementary tasks make each other easier to perform - increasing marginal effort on one task will make it easier to succeed on another task. Substitute tasks are the opposite - increasing marginal effort on one task will make it more difficult to succeed on another task. ${ }^{25}$ An agent faced with multiple goals that are all complementary will perform those goals better than an agent performing multiple goals together that are substitutes. ${ }^{26}$ The reason for this is intuitively simple. Take an agent who is tasked with four tasks, and whose pay (or other form of non-monetary incentive) depends on success on each of those four tasks. If doing task A makes the agent's job easier for tasks B, C, and D, and accordingly results in higher pay or other incentives, the agent is surely going to do more of task A. However, if task A makes the agent's job harder for tasks $\mathrm{B}, \mathrm{C}$, and $\mathrm{D}$, then the agent has a strong incentive to avoid task A, and instead maximize effort or output for the other three tasks for which he will be rewarded. ${ }^{27}$

The second insight is that tasks that are more easily measured are more likely to be performed at a higher level by an agent as compared to tasks that are harder to measure - at least where the principal's incentives for the agent are based on those measurements. ${ }^{28}$ Again, the intuition is relatively straightforward. Consider a situation where task $\mathrm{A}$ is very hard to measure - resulting in large errors (either up or down) in actually evaluating the agent's performance on the task - but tasks B, C, and D are very accurately measured - resulting in very small errors, and again where the agent's compensation depends on those measurements of performance based on tasks $A$, $\mathrm{B}, \mathrm{C}$, and D. ${ }^{29}$ Because of the difference in accuracy of the measurement of

possibility of consolidating or splitting agencies in order to overcome the problems of multiple-goal agencies.

In the context of multiple-goal agencies, the single principal can be seen as an amalgam of Congress, the President, and the public (which elects both the Congress and the President and may also have control over the agencies as well through public pressure, lobbying, etc.). This Article focuses primarily on the statutory language as the "instructions" handed by the principal to the agent, and accordingly as the source of the multiple goals that the agent must follow. Thus, Congress is the primary principal for purposes of this Article. Of course, the real world is much less simple than this, and there are complexities that arise from the existence of multiple principals and their interactions. In particular, in the case studies used throughout this piece as various examples of the dynamics of multiple-goal agencies, it is a simplification to see Congress as the sole principal. Nonetheless, that simplification is worthwhile and the analysis provided through the case studies is accurate.

${ }^{25}$ See Dixit, supra note 18, at 704.

${ }^{26}$ See id. at 705; Bengt Holmstrom \& Paul Milgrom, Multitask Principal-Agent Analyses: Incentive Contracts, Asset Ownership, and Job Design, 7 J.L. Econ. \& ORG. (SPECIAL Issue) 24, 32-33 (1991).

${ }^{27}$ See Holmstrom \& Milgrom, supra note 26, at 31-33 (formally developing this model). For an extension of this model, see John S. Hughes, Li Zhang \& Jai-Zheng James Xie, Production Externalities, Congruity of Aggregate Signals, and Optimal Task Assignments, 22 CoNTEMP. ACCT. Res. 393 (2005).

${ }^{28}$ See Holmstrom \& Milgrom, supra note 26, at 26-28.

${ }^{29}$ The principal's evaluation of performance may be based on effort-measures or outputmeasures. 
performance on different tasks, the agent has much more control over the evaluation of his performance on tasks B, C, and D. Accordingly, the agent will (all things being equal) perform better on the more easily measured tasks. ${ }^{30}$

These two key insights lead to the following general theory: Where an agency is faced with multiple goals, it will tend to overproduce on the goals that are complements and the goals that are easily measured, and it will tend to underproduce on the goals that are substitutes and the goals that are hard to measure.

The significance of this theory is that it predicts distortions in the incentive structures of public agencies regardless of whether the agent's goals are aligned with the principal's goals. In fact, even if the agent does not seek to pursue different goals from the principal, the distortions described above will still occur. ${ }^{31}$ Thus, agencies will systematically overperform on easily measured goals that conflict with harder to measure goals even if there are no problems such as agency capture and significant agency slack. ${ }^{32}$ Indeed, given the frequency of potentially conflicting goals in government, ${ }^{33}$ this problem may be as or more pervasive than capture and slack problems. Likewise, even in the simplified scenario being analyzed here, where there is only one principal, these distortions to the performance of public agencies

${ }^{30}$ See id. at 33-38 (using formal analysis to explore this dynamic in the context of showing that it leads to the prevalence of the use of fixed wages rather than variable, incentivebased wages). For various papers making this general point, see also Michael Barrow, Public Services and the Theory of Regulation, 24 PoL'Y \& PoL. 263, 269-70 (1996); Ken S. Cavalluzzo \& Christopher D. Ittner, Implementing Performance Measurement Innovations: Evidence from Government, 29 ACCT. ORG. \& Soc'Y 243, 247 (2004); Pascal Courty \& Gerald Marschke, Dynamics of Performance-Measurement Systems, 19 Oxford Rev. ECON. POL'y 268 (2003); Mathias Dewatripont, Ian Jewitt \& Jean Tirole, Multitask Agency Problems: Focus and Task Clustering, 44 EuR. ECON. REv. 869, 871-72 (2000); Karen Eggleston, Multitasking and Mixed Systems for Provider Payment, 24 J. Health Econ. 211 (2005); Jean Tirole, The Internal Organization of Government, 46 OXFord ECON. PAPERs 1, 6-7 (1994). Some of the predictions from this model (but not the predictions relevant for this Article) have been challenged based on limited empirical data. See Nicolai J. Foss \& Keld Laursen, Performance Pay, Delegation and Multitasking Under Uncertainty and Innovativeness: An Empirical Investigation, 58 J. ECON. Behav. \& ORG. 246 (2005).

${ }^{31}$ Note that the principal must be uncertain as to whether the agent's goals align with the principal's. If the principal is certain that the parties' are aligned (including exertion of effort), then the principal will have no difficulties providing the maximum reward to the agent for success on all goals. But if the principal is uncertain about the agent's pursuit of the principal's goals, then a monitoring and reward system is essential. However, once that system is established, the distortions discussed above may occur, even if the agent's goals are in fact aligned with the principal. Accordingly, while the most recent formal treatment of the multiple-goal principal-agent problem assumed divergent preferences between the overseer and the agent, nonetheless the distortion problem can still occur even if preferences are aligned. See Ethan Bueno de Mesquita \& Matthew C. Stephenson, Regulatory Quality Under Imperfect Oversight, 101 Am. Pol. SCI. Rev. 605, 607-08 (2007).

${ }^{32}$ See, e.g., id. at 605 (providing brief introduction to the relevant literature and issues); Michael E. Levine \& Jennifer L. Forrence, Regulatory Capture, Public Interest, and the Public Agenda: Towards a Synthesis, 6 J.L. Econ. \& ORG. 167 (1990) (discussing problems that agency capture and slack might create for agency performance).

${ }^{33}$ See supra Part II.A. 
will occur. Thus, the problem of multiple-goal agencies is perhaps one of the most fundamental problems that an institutional and legal designer will have to address in developing a regulatory system.

There are, of course, limitations in directly transferring a principalagent literature originally developed for the private sector to public agencies. Most notably, incentives provided by the principal to the agent for performance on various goals will be much less finely tuned in the public sector than they will be in the private sector. ${ }^{34}$ However, there are tools that are available to principals, whether Congress or the President. Congress might call in agency heads for unpleasant oversight hearings, cut or increase budgets, or increase or decrease the scope of the agency's jurisdiction. The President might block regulatory or other policy initiatives by the agency, remove political appointees, and increase or decrease the size of the agency's budget requests. ${ }^{35}$ Thus, there are incentives that principals can provide in the public sector that can motivate agents to perform better on some or all of their goals.

But compared to the private sector, these various efforts to reward or sanction agents are relatively more costly in terms of the principal's time and energy. Oversight hearings have to be called and attended by members of Congress. The President (or officials in the White House) must take valuable time to identify an agency's failure to comply and determine a suitable punishment. This adds an additional layer of complexity to the analysis to the extent that our solutions for the multiple-goal agency problem requires additional effort and work by the principal to implement, they may be less feasible. After all, the entire point of delegation in the first place is to save the principal time.

\section{Can Agencies Solve the Problem Themselves?}

The above analysis portrays the government agency as a victim of the forces of conflicting goals and problematic measurement - agencies are trapped by their inability to demonstrate to their principals that they are, indeed, achieving on all of the relevant goals, and so they systematically face an incentive to underachieve on the conflicting, difficult-to-measure goals. Again, given the widespread presence of multiple-goal agencies in government, and the potential for those goals to conflict, this appears to be a significant challenge. The result is a less-than-optimal outcome for all par-

${ }^{34}$ This is true for various reasons, such as civil service rules that prevent the easy termination of government employees, demotion, or reduction of pay. See, e.g., JACK H. KNOTT \& Gary J. Miller, Reforming Bureaucracy: The Politics of Institutional Choice 231-37, 240-50 (1987) (noting history of civil service rules in United States limiting ability to dismiss civil service employees); see also Dep't of Navy v. Egan, 484 U.S. 518, 522 (1988) (noting procedural protections for civil service employees against termination); Lindahl v. Office of Pers. Mgmt., 470 U.S. 768, 774-75 (1985) (same).

${ }^{35}$ As an example of this type of control by the principal, see the discussion of OMB oversight, infra Part IV.B.1. 
ties - principal and agent. ${ }^{36}$ But in theory at least, it would seem that agencies do not have to be trapped as victims of the dynamic laid out above. Instead, agencies should have an incentive to solve the problem themselves by attempting to overcome the difficulty of measuring performance on particular goals - through technological or organizational innovation, for instance. ${ }^{37}$ And if agencies can solve the problem themselves, then there is no reason for outsiders (including the principal) to step in with institutional design solutions. ${ }^{38}$ Unfortunately, the solution is probably not so simple in practice.

\section{Limits on the Ability of Agencies To Solve the Problem Themselves}

At one level, there are obvious limits to a strategy of adaptation by agencies. Some goals may simply not be measurable given the current state of technical information, and may never be easily measurable. ${ }^{39}$ Challenges to measurement might arise either because of technical challenges (i.e., an inability to measure a particular goal) or because the goal is so subjective and value-laden that "objective" measures of the goal are impossible to find.

Such challenges are not hard to find in the world of federal agencies, particularly public land management agencies. ${ }^{40}$ As an example of the first challenge, consider efforts to study the status and condition of rare and endangered species, the protection of which is a goal for many federal agencies. Many of these species are often secretive and hard to detect, whether because of scarcity, shyness, or challenging terrain (whether terrestrial or aquatic). The technical challenges of obtaining information about these species - even basic counts of numbers, let alone important habitat, life history, or threat information needed to protect and restore the species - are daunting to say the least. ${ }^{41}$ As a result, it may be effectively impossible for us to obtain satisfactory information about many rare and endangered spe-

\footnotetext{
${ }^{36}$ Bueno de Mesquita \& Stephenson, supra note 31, at 613.

${ }^{37} \mathrm{See} i \mathrm{id}$. at 613 . In reaching their conclusion that agencies will have an incentive to innovate to overcome the problems with observable effort, Bueno de Mesquita and Stephenson do not explore whether that innovation effort will itself be costly and in conflict with performance on the other goals (both observable and unobservable). Thus, it is an open question whether, taking into account the costs of innovation in increasing the observability of outcomes, agencies will always have an incentive to innovate. Nonetheless, this Article's analysis follows Bueno de Mesquita and Stephenson in concluding that agencies will have an incentive to innovate. To the extent that this is not the case, the need for addressing the multiple-goal problem will be accentuated.

${ }^{38}$ See id.

${ }^{39}$ See id. (noting this potential limitation).

${ }^{40}$ See Young Han Chun \& Hal G. Rainey, Goal Ambiguity in U.S. Federal Agencies, $15 \mathrm{~J}$. Pub. Admin. Res. \& Theory 1, 5 (2005) (noting widespread nature of this problem in federal agencies).

${ }^{41}$ See generally Simon Bell \& Stephen Morse, Sustainability Indicators: MeasurING THE IMMEASURABLE? 54-55 (1999) (noting the difficulties of developing quantitative measures for environmental problems).
} 
cies given our current state of technical skill, or even given future advances in technical skill.

As an example of the second challenge, consider goals such as preserving scenic beauty or the quality of a wilderness experience. ${ }^{42}$ Both goals are fraught with subjective value judgments. ${ }^{43}$ The Wilderness Act of 1964 defines wilderness "quality" lands as "an area where the earth and its community of life are untrammeled by man, where man himself is a visitor who does not remain." 44 Attempts by agencies to quantify and measure the wilderness quality of various lands have accordingly been contentious and bitterly fought, with each side alleging that the other has misstated the true status of wilderness on the ground. ${ }^{45}$

Measurement of other goals may be technically feasible, but impracticable. For instance, it may be technically feasible for agencies to obtain detailed measurements of some species of wildlife or other environmental conditions, but the costs may be exorbitant. ${ }^{46}$

${ }^{42}$ Both are goals set out for many public land management agencies. See, e.g., 16 U.S.C. $\S 528$ (2000) ("It is the policy of the Congress that the national forests are established and shall be administered for outdoor recreation, range, timber, watershed, and wildlife and fish purposes."); id. § 529 ("The establishment and maintenance of areas of wilderness are consistent [with the statutory purpose]."); 43 U.S.C. \& 1712(c)(1) (2000) (setting "multiple-use" as a goal for BLM land use planning); id. $\S 1702$ (c) (defining multiple use as including "natural scenic . . . values"); id. $\S 1782$ (requiring BLM to conduct a wilderness study for its lands).

${ }^{43}$ See, e.g., George Cameron Coggins, The Law of Public Rangeland Management IV: FLPMA, PRIA, and the Multiple Use Mandate, 14 ENvTL. L. 1, 87-88 (1983) ("Some attributes, such as scenic quality, cannot be measured with precision; others, such as recreational value, have been quantified only in extremely narrow or wildly subjective ways.").

${ }^{44} 16$ U.S.C. $\$ 1131$ (c) (2000). The statute further defines wilderness as an area that "(1) generally appears to have been affected primarily by the forces of nature ...; (2) has outstanding opportunities for solitude or a primitive and unconfined type of recreation; (3) has at least five thousand acres of land or is of sufficient size as to make practicable its preservation and use in an unimpaired condition; and (4) may also contain ecological, geological, or other features of scientific, educational, scenic, or historical value." Id.

${ }^{45}$ See, e.g., Utah v. Babbitt, 137 F.3d 1193, 1197-1200 (10th Cir. 1998) (describing the extended battle among environmental groups, the State of Utah, and BLM over the quality of BLM's survey of its lands for wilderness characteristics in the early $1980 \mathrm{~s}$ and its designation of areas as potential wilderness areas); see also Stephen H.M. Bloch \& Heidi J. McIntosh, A View from the Frontlines: The Fate of Utah's Redrock Wilderness Under the George W. Bush Administration, 33 GoldEN GATE U. L. REv. 473, $477-78$ (2003) (noting the various estimates of wilderness-quality lands in Utah produced by BLM and environmentalist surveys, ranging from 3.4 to over 9 million acres); Clare Ginger, Interpreting Roads in Roadless Areas: Organizational Culture, Ambiguity, and Change in Agency Responses to Policy Mandates, 29 ADMIN. \& Soc'Y 723, 741-42 (1998) (noting challenges of defining the meaning of the term "road" for wilderness surveys by BLM).

${ }^{46}$ One researcher in the mid-1980s estimated that obtaining full information about annual changes in the population of one major bird species in one national forest could exceed one million dollars per year. See Jared Verner, Future Trends in Management of Nongame Wildlife: A Researcher's Viewpoint, in Management of Nongame WiLdLIfe in tHe Midwest 149, 159 (J.B. Hale et al, eds., 1986). As another example, Sen. John McCain has regularly used a multi-million-dollar study of grizzly bear DNA as an example of the excesses of earmarks and pork spending. Whatever the merits of the Senator's critique, the study - which was designed to give an accurate estimate of the size of a threatened grizzly population in northern Montana - shows the expense of many wildlife studies. See Coco Ballantyne, McCain's Beef with Bears? - Pork, ScI. Am., Feb. 8, 2008, http://www.sciam.com/article.cfm?id=mccains-beefwith-bears (on file with the Harvard Environmental Law Review). 
In all of these situations, there is little, if anything, that the agency or the overseer could do to improve the measurement of the relevant goals so as to ameliorate the conflict among multiple goals. More information is not available and cannot practically be obtained. But even in the universe of goals for which better measurement might be achievable and practicable, there can be internal obstacles that prevent an agency from improving its ability to measure performance on certain goals. Agencies, for their own reasons, may be "fixated" on particular goals such that they do not have internal incentives to improve their ability to measure performance on others, even if measurement improvements might otherwise allow them to improve performance on all of their goals.

One primary reason this might come to pass is because of the need for agencies to motivate their own employees. Public agency work is frequently paid much less than private sector work in the same field, and the ability of government agencies to provide the kind of pay and bonus incentives that can be used to motivate private sector employees is quite limited (often by civil service rules). Whatever the merit of these kinds of limitations, they may result in agencies relying on other tools to hire, retain, and motivate skilled employees, such as orienting their work around a specific mission that appeals to the employees the agency would like to hire and retain. ${ }^{47}$ Public schools, for instance, might orient around a mission of serving disadvantaged children in order to attract qualified job applicants who might otherwise enter into other professions; and public hospitals might orient around a mission of saving lives in poor communities to retain doctors who might otherwise go into a lucrative private practice specialty.

There is another reason that an agency might choose to "focus" on a particular mission. Where an agency has goals that are inherently difficult to measure - whether because of insurmountable technical difficulties or because of the inherent subjectivity of the goal - there will necessarily be a cost to evaluating the performance of the agency's employees on those fuzzy goals. ${ }^{48}$ That cost will result in suboptimal provision of rewards or incentives to employees while they are with the agency, and will also make it difficult for employees who are leaving the agency to demonstrate to future employers the quality of their work in their prior job. ${ }^{49}$ Both factors will deter employees from working with government agencies and will also reduce performance within the agency. To address this problem, agencies again may adjust by focusing on particular missions, and hiring professionals who are trained to achieve those missions. As a result the agency can narrow the vague and broad goal to one that may be more measurable and

${ }^{47}$ See Timothy Besley \& Maitreesh Ghatak, Competition and Incentives with Motivated Agents, 95 Am. ECON. Rev. 616 (2005).

${ }^{48}$ See Mathias Dewatripont, Ian Jewitt \& Jean Tirole, The Economics of Career Concerns, Part II: Application to Missions and Accountability of Government Agencies, 66 REv. Econ. STUD. 199 (1999).

${ }^{49}$ See id. 
accountable, and solve its problems of monitoring and providing incentives to employees. ${ }^{50}$

A third reason why an agency might have "fixed" on a particular mission at the expense of other goals, even those that it could in theory measure better and perform better on, is historical path-dependence. For example, an agency might originally have had a narrower range of goals, but only recently had a new goal added to its requirements. In this case historical inertia within the organization might result in the inability of the agency to adapt to the new circumstance. Similarly, an agency may have historically relied heavily on a particular professional orientation or outlook to staff its agency, and as a result may have difficulty adapting its internal culture to the new range of goals it is expected to achieve. ${ }^{51}$

\section{Evidence of the Inability of Agencies To Solve the Problem Themselves: A Case Study of the U.S. Forest Service}

Whatever the reason, there is substantial empirical evidence that agencies at times fixate on particular missions, even when the principal has expanded the number of goals the agency is supposed to take into account. James Q. Wilson's classic study of bureaucracy provides ample anecdotal evidence that federal agencies systematically narrow the range of their goals from the ones imposed on them by Congress. ${ }^{52}$ For instance, Wilson points out that the Federal Bureau of Investigation ("FBI") historically had a strong focus on investigating bank robberies and kidnappings, to the detriment of drug distribution and other organized crime, primarily because of the ease of investigating and prosecuting the former types of crimes, and the risk of scandal and corruption associated with the latter types of crimes. ${ }^{53}$

As a case study of this dynamic, consider the Forest Service ("the Service"). Congress (the principal) created the Forest Service (the agent) around the turn of the twentieth century and tasked it with managing national forests to protect watershed resources and produce timber - at least according to the organic statutes establishing the national forest system..$^{54}$

${ }^{50}$ See id.; see also Tirole, supra note 30 , at 10-11.

${ }^{51}$ See Jerry L. Mashaw, Improving the Environment of Agency Rulemaking: An Essay on Management, Games, and Accountability, Law \& Contemp. Probs., Spring 1994, at 185, 211 (discussing importance of professional orientations in determining agency priorities).

${ }^{52}$ WILSON, supra note 17 , at 101, 158, 371-72 (noting common nature of this pattern, and arguing that focused missions may be important for agency morale and performance).

${ }^{53}$ Id. at $107-08$.

${ }^{54}$ See Act of June 4, 1897 (Forest Service Organic Act), ch. 2, 30 Stat. 11, 35 (repealed 1976). The national forest system was originally managed by the Department of the Interior, but management responsibility was later transferred to the Bureau of Forestry in the Department of Agriculture, which became the Forest Service. See Samuel Trask Dana \& Sally Fairfax, Forest and Range Policy 81-82 (2d ed. 1980).

As noted earlier, for purposes of making analysis tractable, this Article treats the single principal that is providing instructions to the agency as equivalent to Congress, the drafter of the statutory "instructions." See supra note 24 and accompanying text. Of course, this is a simplification, as there are significant roles in the American political process for the President, the public (both in general, and in specific groups), and the courts in guiding Forest Service 
Over time, Congress expanded the Service's mission to explicitly include goals such as wildlife, recreation, and grazing. This shift began with the passage of the aptly named Multiple-Use Sustained-Yield Act ("MUSYA") in 1960 to include a range of goals in addition to timber and watershed protection - such as range, wildlife and fish, and recreation. ${ }^{55}$ In 1976, responding both to court decisions that had questioned the Forest Service's authority to use clear-cutting as a management tool, and public pressure to limit the use of clear-cutting, Congress passed the National Forest Management Act ("NFMA"), which provided more explicit requirements as to the additional goals that the Service was required to pursue, including requirements that the Service maintain diversity of wildlife and plant species, protect against soil erosion, and protect scenery on the public lands..$^{56}$

Thus, today the Forest Service is faced with the mandate to manage public lands for a number of multiple-use goals, ranging from protection of wildlife, scenic, and recreational resources, to protecting soil and water quality, to production of timber, to providing opportunities for grazing and mineral exploitation, among others. These goals are obviously substitutes. A clear-cut timber project will directly conflict with a proposal to create a pristine wilderness area in the same location. Providing more effort here to

actions and providing "instructions." See infra notes 100-103 and accompanying text. Nonetheless the following discussion is accurate enough to support this Article's point.

Relatedly, this Article treats the substantive statutes that created the Forest Service and provide standards, goals, and constraints for its activities as the "instructions" that guide the agent. This is also a simplification. Procedural statutes can do much to guide an agency's decision-making process, by increasing or reducing the costs of various options. See Matthew D. McCubbins, Roger G. Noll \& Barry R. Weingast, Administrative Procedures as Instruments of Political Control, 3 J.L. Econ. \& ORG. 243 (1987). Likewise, Congress's use of its appropriations powers and its oversight authority can significantly alter the behavior of an agency in a way that is not apparent from the substantive statutes. See infra note 101 and accompanying text. Nonetheless, the substantive statutes are the most explicit set of instructions that Congress provides to the agency, and can provide a starting point for this analysis. This Article does not contend that, in the case of the Forest Service, those other forms of control by Congress have significantly changed the goals of the agency from those articulated in the governing statutes (although they certainly may have affected the agency's emphasis among those goals). See infra notes 102-103 and accompanying text. In particular, with respect to appropriations and oversight decisions, which are made by a subset of Congress (i.e., committees), there is a strong argument that Congress as a whole (i.e., the principal for purposes of our analysis) is not the true actor, because there are significant differences between the preferences of Congress as a whole and the committees, and Congress as a whole is often unable fully to regulate the activities of committees. See Christopher H. Foreman, JR., Signals from the Hill: Congressional Oversight and the Challenge of Social Regulation 101-02 (1988); Michael W. Kirst, Government Without Passing Laws: Congress' Nonstatutory TEChNiques for APPROPRIATIONS Control 139, 145-46 (1969). (2000)).

ss Pub. L. No. 86-517, 74 Stat. 215 (1960) (codified as amended at 16 U.S.C. $\$ \S 528-531$

${ }_{56}$ Pub. L. No. 94-588, § 6, 90 Stat. 2949, 2954-55 (1976) (codified at 16 U.S.C. $\S 1604(\mathrm{~g})(3)(2000)$ ); see, e.g., 16 U.S.C. $\S 1604(\mathrm{~g})(3)(\mathrm{E})(\mathrm{i})$ (requiring the agency to develop forest management planning regulations that provide protection for "soil, slope or other watershed conditions"); id. $\S 1604(\mathrm{~g})(3)(\mathrm{B})$ (requiring the agency to "provide for diversity of plant and animal communities"); id. \& $1604(\mathrm{~g})(3)(\mathrm{F})(\mathrm{v})$ (requiring that clearcuts be performed "in a manner consistent with the protection of soil, watershed, fish, wildlife, recreation, and esthetic resources"). 
accomplish one task (providing timber from the public lands) makes it a lot harder for the agency to accomplish another task (providing wilderness areas). In addition, many of these goals (particularly environmental ones) are relatively difficult to measure. As noted above, some will be technically difficult to measure (such as wildlife numbers) while others (for instance, the visual beauty of a landscape) will be subjective at best. Moreover, even the "numerical" measures have a misleading appearance of precision about them. Where and how to measure an indicator will have dramatic impacts on the actual measurement and on its relevance to the underlying environmental amenities that the measurement is intended to cover. Finally, there are also serious problems connecting any numerical indicator to the efforts (either positive or negative) of the Forest Service as a manager - a stream may be contaminated because of the pollution of any one of several neighboring landowners, despite the best efforts of the Forest Service to try to clean up its activities in the watershed.

Nonetheless, we would expect efforts by the Forest Service to overcome at least some of the technical obstacles to the measurement of environmental quality. Undoubtedly, the Service has done so to some extent. But the changes in the Forest Service's explicit legislative mandate in 1960 and 1976 to include a full range of multiple-use goals initially had a halting and limited impact on the Service's own production of information about its performance on that expanded range of goals, as well as on its performance. Throughout the late 1970 s and 1980 s, the Forest Service continued to increase timber production on its lands, often at substantial environmental cost. $^{57}$ Outside commentators regularly claimed that the Forest Service as an agency was primarily focused on timber as its primary or even only output, rather than on the other goals it was theoretically required to consider under its governing statutes. ${ }^{58}$ A survey of Forest Service employees in 1990

${ }^{57}$ See, e.g., Paul W. HiRt, A Conspiracy of Optimism: Management of the NaTIONAL FORESTS SINCE WORLD WAR Two 271-72 (1994) (noting that the Forest Service increased timber quotas for harvesting on its lands in the 1980s); NANCY Langston, Forest DREAMS, Forest NightMAREs 264-68 (1995) (noting increased timber harvesting on Forest Service lands in Blue Mountains in eastern Oregon and Washington in the 1980s); CHARLes F. Wilkinson, Crossing the Next Meridian: Land, Water, and the Future of the West, 146 (1992) (noting that timber output on national forest lands in 1980s was equal to that of the 1960s); YAFFEE, supra note 2, at 65-66 (noting agency and congressional pressure to increase cut in timber); Federico Cheever, Four Failed Forest Standards: What We Can Learn from the History of the National Forest Management Act's Substantive Timber Management Provisions, 77 OR. L. Rev. 601, 693 (1998) (citing Forest Service statistics showing logging levels on national forest lands reached historic highs in the 1980s). Of course, a significant part of the reason for higher timber production by the Forest Service in this period was pressure from congressional appropriations committees and President Reagan. See infra note 100-103 and accompanying text.

${ }^{58}$ See, e.g., Select Comm. of the Univ. of Mont., A University View of the Forest SERviCE, S. Doc. No. 91-115, at 13-14 (1970) (arguing that Forest Service management of the Bitterroot National Forest in Montana was an example of timber goals overriding all other goals); Jeanne Nienaber Clarke \& Daniel C. McCool, Staking Out the Terrain: Power and Performance Among Natural Resource Agencies 54, 57-58, $62-63$ (1996) (noting Forest Service's close relationships with timber companies, and how political appointees in agency successfully pushed it to greatly increase timber output in 1980 s, albeit with internal 
found that they too believed that the Service was heavily focused on timber production versus other goals. ${ }^{59}$ In its forest planning process, the Service would regularly seek to increase timber cut levels from the 1920s through the $1980 \mathrm{~s} .{ }^{60}$ Even where the Service did consider other goals, such as "community stability," those goals were often used to justify the production of more timber. ${ }^{61}$

Particularly relevant for our purposes is the Service's reluctance to compile information about the impacts of its management practices on other goals, especially relating to wildlife. In the Pacific Northwest, for instance, wildlife biologists in the 1970s started raising concerns about the impacts that massive logging of old-growth forests were having on old-growth dependent species such as the spotted owl. ${ }^{62}$ However, the Forest Service was slow to compile information about the spotted owl and other old-growth wildlife. ${ }^{63}$ It is an open question whether, in that context, more information

resistance from some lower-level staff); Christopher McGrory Klyza, Who Controls Public LANDS? 18-20 (1996) (arguing that the Forest Service was oriented toward timber production through the 1980s); Robert H. Nelson, Mythology Instead of Analysis: The Story of Public Forest Management, in Forestlands: Public and Private 23 (Robert T. Deacon \& M. Bruce Johnson eds., 1985) (criticizing the Forest Service as being overly focused on timber production as a goal in and of itself, even where economically infeasible); WILKINSON, supra note 57, at 24-25 (arguing that Forest Service has bias in favor of timber production); WILSON, supra note 17, at 63 (arguing that Forest Service has committed to particular logging techniques despite criticism about impacts of those techniques on other values); YAFFEE, supra note 2, at 40-44 (stating that through the end of 1970s Forest Service continued to focus on timber); Mark W. Brunson \& James J. Kennedy, Redefining "Multiple Use": Agency Responses to Changing Social Values, in A New Century for Natural Resources ManageMENT 143, 145-46, 151 (Richard L. Knight \& Sarah F. Bates eds., 1995) (noting Forest Service's almost exclusive focus on timber production in 1950s and 1960s and the difficulties the agency had in shifting its focus to other goals); Jeff DeBonis, Natural Resource Agencies: Questioning the Paradigm, in A New Century for Natural Resources Management, supra, at 159, 160 (noting that Forest Service would ignore environmental harm to meet timber quotas); Joseph L. Sax \& Robert B. Keiter, Glacier National Park and lts Neighbors: A Study of Federal Interagency Relations, 14 ECOLOGY L.Q. 207, 215 (1987) (identifying "old school" of Forest Service as being "strongly oriented toward traditional commodity uses of the forest").

${ }^{59}$ See Greg Brown \& Charles C. Harris, The U.S. Forest Service: Toward the New Resource Management Paradigm?, 5 Soc'y \& Nat. Resources 231, 238 (1992); see also Paul Mohai et al., U.S. Dep't of Agric., Forest Service, Gen. Technical Report NC-172, Change in the USDA Forest Service: Are We Heading in the Right Direction? 8-9, 70 figs.8 \& 9 (1994) (reporting survey showing that Forest Service employees believe agency should focus primarily on non-commodity resources such as wildlife and recreation, but that timber is the agency's primary goal).

${ }^{60}$ See David A. Clary, Timber and the Forest Service 78, 91, 121-22, 156-58, 169-79 (1986); see also id. at 116-19 (discussing efforts by the Forest Service after World War II to greatly increase road construction in national forests to allow for greater access to timber resources).

${ }^{61}$ See Louise P. Fortmann, Jonathan Kusel \& Sally K. Fairfax, Community Stability: The Foresters' Fig Leaf, in COMmunity Stability IN Forest-Based Economies 44, 44-45 (Dennis C. Le Master \& John H. Beuter eds., 1989) (arguing that Forest Service uses goal of "community stability" to advance goals of producing timber and supporting timber industry).

${ }^{62}$ See YAFFEE, supra note 2, at 14-35.

${ }^{63}$ According to one observer, the agency's failure to compile information was based on the agency's desire not to obtain more information that might interfere with the production of more timber from old-growth forests. See id. at 17 (noting that Forest Service officials had a 
earlier might have resulted in different decisions by the Forest Service, given the political, economic, and social constraints the Service faced. However, it is possible that the spotted owl conflict in the 1980s and 1990s might have been averted or alleviated if the information that would have justified aggressive action to protect old-growth had been available. ${ }^{64}$

The spotted owl controversy is not an isolated example. In general, the Service's planning process regularly used assumptions that favored the production of more timber, while often limiting the information collected to data that would support more timber production. ${ }^{65}$ A General Accounting Office ("GAO") study from March 1991 found that both BLM and the Forest Service provided minimal funding for wildlife protection and regularly decided against more wildlife protection in their planning processes ${ }^{66}$ The lack of funding and prioritization had its greatest impact on the collection of information about wildlife resources on the public lands: GAO found that the agencies regularly failed to fulfill planning commitments to monitor impacts of land-use decisions on wildlife, and had little information about the status of wildlife in general on public lands ${ }^{67}$ A subsequent study by the congressional Office of Technology Assessment ("OTA") in 1992 likewise found inadequate monitoring of wildlife and other environmental factors by the Forest Service, an inadequacy that the OTA concluded had hindered the Service's ability to plan for its full range of multiple uses. ${ }^{68}$

Why was the Forest Service slow to gather information about the status of wildlife on its lands, and the impacts of its management actions on wildlife, when Congress had explicitly set out wildlife as one of its goals? Causation in this case is probably overdetermined, the result of a range of factors including pressure from the White House and from important members of

\footnotetext{
"fundamental desire not to know more" about logging impacts on spotted owl "because knowledge could only conflict with current management directions"); id. at 24-26 (noting lack of basic information in Forest Service about wildlife and ecology of Northwest old-growth forests, and resistance to compiling what information was known because it "might provide the basis for outsiders to challenge the decisions of line [Forest Service] officers").

${ }^{64}$ Yaffee argues the lack of information was used by the Forest Service to justify not taking action to protect the spotted owl. See id. at 29 (citing participant in agency decision making stating that agency officials would refuse to commit to changes in timber management because of lack of "adequate data").

${ }^{65}$ See Randal O'ToOle, Reforming the Forest Service 62-68, 74-77, 81, 86 (1988) (giving examples of these dynamics in Forest Service planning).

${ }^{66}$ U.S. Gen. Accounting Office, Public Land Management: Attention to Wildlife Is LiMITED 2-16 (1991).

${ }^{67}$ See id. at 21, 25, 29-33; see also id. at 25 ("Of major importance, monitoring programs in the agencies' plans were usually not performed. Without monitoring, the agencies do not have the information needed to determine the effect their actions are having on wildlife and make appropriate adjustments to their plans."). Attitudes of Forest Service employees in the early 1990s likewise reflected a concern that the agency needed to collect more information about wildlife. See Mohal ET AL., supra note 59, at 10, 32 tbl.5 (1994) (noting that proposals to collect more information about wildlife received most support in survey of Forest Service employees).

${ }^{68}$ See Office of Tech. Assessment, U.S. Congress, Forest Service Planning: Accommodating Uses, Producing Outputs, and Sustaining Ecosystems 6, 11, 21, 110, 120 (1992); see also id. at 115 (finding inconsistent requirements for monitoring and resource inventories under different Forest Service plans).
} 
Congress $^{69}$ - but this Article will focus on the possibilities that support the theoretical arguments laid out above.

There is substantial evidence that, at least during the 1970s and earlyto mid-1980s, many Forest Service employees had a mission orientation that focused on timber production. Studies of employee attitudes toward timber production in the early 1980s showed that employees generally favored timber production over environmental protection. ${ }^{70}$ Apparently, the Forest Service's own computer programmers had a similar orientation: Some of the Service's computer models that it used in the 1970s and 1980s for developing its forest plans favored timber production, requiring a minimum amount of timber production no matter what the impact on other resources, and in general those models had only a limited ability to consider the role of nonmarket commodities such as scenery, wilderness, and wildlife diversity. ${ }^{71}$

${ }^{69}$ See Select Comm. of the Univ. of Mont., A University View of the Forest SerVICE, S. Doc. No. 91-115, at 14 (1970) (studying of Forest Service management of Bitterroot National Forest, concluding timber was the agency's overriding goal, and stating that "heavy timber orientation is built in by legislative action and control, by executive direction and by budgetary restriction. It is further reinforced by the agency's own hiring and promotion policies and ... rationalized in the doctrines of its professional expertise"). Certainly pressures placed on the Forest Service by congressional appropriations committees and the White House to increase timber production at all costs played a role. See infra notes 100-101 and accompanying text.

Another possibility is that "wildlife" as a term had a very different meaning in 1960 (when MUSYA was passed) and in the 1980s. In the 1960s, the focus of wildlife managers was on "game" species such as deer, turkey, and elk, but by the 1980s, wildlife had expanded to include a wide range of diverse "non-game" species that included plants, invertebrates, reptiles, and amphibians. Compare Langston, supra note 57, at 235 (noting that in 1930s wildlife was exclusively seen as game species), with 16 U.S.C. $\$ 1532(8)$ (2000) (broad language of 1973 ESA defining "fish or wildlife" to include "any member of the animal kingdom, including without limitation any mammal, fish, bird ... amphibian, reptile, mollusk, crustacean, arthropod or other invertebrate"). The Forest Service has been characterized as overly focused in its management on "game" species rather than on "non-game" species such as the spotted owl. See ClaRY, supra note 60, at 167 (stating that in 1960s and 1970s, Forest Service and the forestry profession primarily saw wildlife as equivalent to deer, which would benefit from many silvicultural techniques). Arguably, then, the Forest Service's actions might have been consistent with congressional intent in the 1960 MUSYA. However, the passage of NFMA in 1976, which explicitly called on the Forest Service to protect the diversity of animal and plant species, a short time after the passage of the ESA and the rise of modern environmentalism, provides a set of instructions much more closely tied to "non-game" wildlife. See 16 U.S.C. $\S 1604(\mathrm{~g})(3)(\mathrm{B})(2000)$.

${ }^{70}$ See Ben W. Twight, Fremont J. Lyden \& E. Thomas Tuchmann, Constituency Bias in a Federal Career System? A Study of District Rangers of the U.S. Forest Service, 22 AdmIN. \& Soc'y 358 (1990) (finding that attitudes toward tradeoffs between environmental protection and timber production among Forest Service field personnel were much more closely aligned with the timber industry than with environmental groups); Ben W. Twight \& Fremont J. Lyden, Measuring Forest Service Bias, J. ForestrY, May 1989, at 35 (same). But see PAUL J. Culhane, Public Lands Politics: Interest Group Influence on the Forest Service and THE BUREAU OF LAND MANAGEMENT (1981) (arguing, based on study of much smaller sample of Forest Service district rangers, that agency effectively balances between industry and environmental demands).

$"$ See HirT, supra note 57, at 274-75; see also OfFICE OF TECH. Assessment, supra note 68 , at 10,135 (noting constraints in FORPLAN, the Forest Service's primary programming tool for planning, which limited its usefulness in managing for non-quantitative outputs); 
This mission orientation among Forest Service personnel, is, at least in part, the legacy of the Forest Service's early history. When the Service was created in the early twentieth century, its founder, Gifford Pinchot, sought to imbue it with a dedication to making the national forests useful and productive for local residents. ${ }^{72}$ Early Forest Service policy and guidance documents emphasized that forests were to be "used" to create timber products for the benefit of the people. ${ }^{73}$ One of the most important of those early guidance documents, a letter from Secretary of Agriculture James Wilson in 1905 that was ghost-written by Pinchot, stated:

All the resources of forest reserves are for use, and this use must be brought about in a thoroughly prompt and businesslike manner $\ldots . . .[T]$ he water, wood, and forage of the reserves are [to be] conserved and wisely used for the benefit of the home builder first of all .... The continued prosperity of the agricultural, lumbering, mining, and livestock interests is directly dependent upon a permanent and accessible supply of water, wood, and forage, as well as upon the present and future use of their resources under businesslike regulations, enforced with promptness, effectiveness, and common sense. ${ }^{74}$

O'Toole, supra note 65 , at 55 (noting one national forest set parameters in its forest planning programs that excluded options without timber cutting).

72 Pinchot's basic conservation philosophy was one in which natural resources were "conserved" to provide the greatest benefit for human use, maximizing the efficient use of the resources. See Samuel P. Hays, Conservation and the Gospel of Efficiency: The ProGRESSIVE CONSERVATION MOVEMENT 1890-1920, ch. 3 (1959); KLYZA, supra note 58, at 15 $18,70-75$ (noting that from outset, Forest Service saw its lands as resources to be used and exploited in a "technocratic utilitarianism" paradigm); James L. Huffman, A History of Forest Policy in the United States, 8 ENVTL. L. 239, 252 (1978) ("[I]t is no secret that Pinchot argued for use and against preservation."). Accordingly, Pinchot pushed for laws that would give federal agencies the authority to allow and encourage commercial use of the new national forests, rather than just allowing the forest to sit and "waste." See GifFord PINCHOt, BreakING New GRound 260 (1947) (stating that transfer of national forests to control of Department of Agriculture (and Pinchot's new Forest Service) was important to ensure the forests' "fullest usefulness" and to prevent wasteful non-management by Department of the Interior). Indeed, Pinchot was actively hostile toward preservationists such as John Muir (who opposed commercial exploitation of natural resources), and was a leader in the fight to allow the Hetch Hetchy Dam in Yosemite National Park. See HAYs, supra, at 127, 189-93, 197; HIRT, supra note 57, at 32, 34 (noting Pinchot's disagreement with preservationist approach).

${ }^{73}$ See, e.g., Gifford Pinchot, U.S. Dep't of Agric., Forest Service, The Use of the NATIONAL FORESTS 7 (1907) (stating, in guiding policy for national forests, that they are for "use of the people," and that before the Forest Service managed the forest reserves, they were "locked up and left to burn"); id. at 11-12 ("The timber is there to be used, now and in the future.").

${ }^{74}$ See Pinchot, supra note 72, at 261 (quoting letter). Pinchot called this letter the "essence of Forest Service policy." Id. at 262. Until at least the early 1990s, this document was still influential in setting Forest Service policy and was included in the agency's official compilation of governing laws and policies. See WILKINSON, supra note 57, at 127-28. In a study of forest rangers in 1960, a researcher stated that not one ranger got through an "interview without at least one reference, directly or by paraphrase, to Gifford Pinchot's creed that the national forests must be managed for the greatest good of the greatest number in the long run." Herbert Kaufman, The Forest Ranger: A Study in Administrative Behavior 207 (1960). 
After Pinchot left the Forest Service, its mission remained essentially the same. The Forest Service emphasized timber production (or the potential for timber production) as its most important goal ${ }^{75}$ - even when such emphasis meant that it would lose political battles against the newly created National Park Service for management of particularly scenic parcels of land such as the Olympic Peninsula of Washington State. ${ }^{76}$ Likewise, in the 1920s the Forest Service changed its perspective on what management prescriptions were necessary to protect watershed values in order to increase timber harvesting on its lands in eastern Oregon and Washington. ${ }^{77}$

This agency mission was effectively transmitted to lower-level employees through hiring, training, and personnel management processes that thoroughly socialized new employees into the Forest Service's mission. Herbert Kaufman's classic 1960 study of the Service's administrative and personnel policies provides ample evidence of how it developed and maintained a work culture focused on the ideals of timber production. ${ }^{78}$ For instance, the Service focused its recruiting almost exclusively on forestry school graduates, with over ninety percent of its professional employees in the 1950s being foresters. ${ }^{79}$ Graduates from these types of programs were particularly receptive to socialization within the Service..$^{80}$ The Service used probationary hiring periods to screen out employees who were not compatible with

${ }^{75}$ See Clary, supra note 60, at 27-28, 35, 74-77, 121-22 (noting focus of the Forest Service on managing its lands for present or future timber production through 1940s); SAMUEL TRask Dana, Forest and Range Policy 326 (1956) (noting that "primary objective" of national forests is timber production and water supply protection); HIRT, supra note 57, at 36 . 37 (noting timber emphasis of the Forest Service in 1930s); id. at 44, 83, 91, 112, 131-36 (same in 1940s and 1950s). In a meeting with timber executives shortly after the passage of MUSYA in 1960, the chief of the Forest Service reassured the executives that "the highest sustained yield production of timber remained a primary agency goal." Id. at 189 .

${ }^{76}$ See Ben W. Twight, Organizational Values and Political Power: The Forest Service Versus the Olympic National Park (1983) (describing how the Forest Service in the 1920s and 1930s remained focused on timber production as opposed to other goals such as recreation or conservation and that as a result the Forest Service lost the battle to control the Olympic Peninsula to the more preservation-oriented Park Service). Pinchot's attitude toward the Olympic Peninsula was that it was a "windfall in timber." PINCHOt, supra note 72, at 127. The Forest Service aggressively cut areas of the Olympic Peninsula that were taken back from protective status and placed under Forest Service control. See HIRT, supra note 57, at 37-38. The Forest Service did move toward the creation of preservation-oriented land designations such as "primitive areas" in the 1920s and 1930s, but partly in response to competition from the Park Service. See Clary, supra note 60, at 102; Dana \& FaIRFax, supra note 54, at 13134, 155-57; KLyzA, supra note 58, at 77-78; R.W. Behan, Political Popularity and Conceptual Nonsense: The Strange Case of Sustained Yield Forestry, 8 ENVTL. L. 309, 314 (1978). Indeed, it was the Forest Service's resistance to the permanent protection of areas from development - the Forest Service would on occasion reclassify previously protected areas - that led environmental groups to push for passage of the Wilderness Act in the 1950s and 1960s. See KLYZA, supra note 58, at 79-80, 90.

${ }_{77}$ See LangSTON, supra note 57 , at 147, 188-89.

${ }^{78}$ KAUfMAN, supra note 74; see also YAFFEE, supra note 2, at 262-63, 265 (noting Forest Service's narrow focus on forestry in hiring and training, and marginalization of wildlife staff).

${ }^{79}$ KAUFMAN, supra note 74, at 166; see also id. at 167 (noting that the "overwhelming number of candidates and appointees to professional vacancies" came from forestry schools).

${ }^{80} \mathrm{Id}$. at 166. 
the Service's culture. ${ }^{81}$ Thus, "[t]hose who make the grade and stick to the Forest Service are therefore men who know the agency and are not at odds with its goals and methods. They have shown an intrinsic readiness and ability to conform." ${ }^{2}$ The Forest Service used both formal and informal training on a near-constant basis to socialize new hires. ${ }^{83}$ The Service's transfer and promotion process encouraged its employees to "internalize' the perceptions, values, and premises of action that prevail" in the Forest Service ${ }^{84}-$ by, for instance, regularly transferring employees among different posts to encourage them to consider the Service, rather than their temporary geographic location, to be their community ${ }^{85}$ The Service hierarchy has historically been entirely staffed by internal promotion of employees with decades of service to the Service, again encouraging loyalty to the organization at all levels within it. ${ }^{86}$ Symbols such as uniforms and badges were also used to good effect by the Service to maintain a strong agency culture. ${ }^{87}$ The overall result was a Forest Service where employees "conform to agency decisions not simply because they have to, but because they want to." 88

Why did the Forest Service historically focus so much on its primary mission of timber production? The simplest answer, but probably not a complete one, is that Congress instructed the Service to focus on timber the original act creating the national forest reserves in 1897 required that the reserves be managed to protect timber and water quality. ${ }^{89}$ Naturally, the Service focused on the goals laid out for it by Congress, and inertia kept it on that path even after Congress expanded the range of goals to be considered by it..$^{90}$

A second explanation is based on the theoretical literature laid out above. Faced with a broad and difficult-to-quantify goal of managing reserves for "conservation" and "wise use," the Forest Service focused on the particular targets that were most easily measured: timber management and production.91 Timber harvests from national forests, for instance, are

${ }^{81}$ Id. at $169-70$ (noting that ten to fifteen percent of new hires left during the initial probationary period).

${ }_{82}$ Id.

${ }^{83}$ Id. at 172 ("In the three to ten years it generally takes a probational forester to reach command of his own district, he is subject - by careful planning, not just by accident - to concentrated training in the form of close supervision.").

${ }^{84}$ Id. at 176.

${ }^{85} \mathrm{Id}$. at $177-79$ ("Only one thing gives any continuity, any structure, to [the ranger's] otherwise fluid world: the Service.").

${ }^{86}$ Id. at $179-83$.

${ }^{87} \mathrm{ld}$. at $183-85$.

${ }^{88} \mathrm{Id}$. at 198.

${ }^{89}$ See Act of June 4, 1897 (Forest Service Organic Act), ch. 2, 30 Stat. 11, 35 (repealed 1976). The timber industry in the 1960s saw the 1897 Act as enshrining timber as a primary focus for the Forest Service. See HIRT, supra note 57, at 183-84.

${ }^{90}$ See, e.g., WILKINSON, supra note 57, at 168-69.

${ }^{91}$ It is true that before World War II, the Forest Service was not as focused on timber harvesting as it was on timber management (i.e., maintaining large reserves of timber for future use). See ClaRY, supra note 60, at 111; Nelson, supra note 58, at 41; YAFFEE, supra note 2 , at 4 . That attitude changed after World War II with the boom in timber demand for new home construction. YAFFE, supra note 2, at 4. Nonetheless, management of the national 
readily quantifiable and easily measured..$^{92}$ Other goals, such as protection of water quality and production due to timber management, or scenic and aesthetic qualities, or wildlife habitat quality, are either difficult to measure technically ${ }^{93}$ or require difficult subjective value judgments. It is therefore no surprise that the Service has historically emphasized timber production and timber quotas for its internal review and evaluation of performance of its

forests was focused primarily on maintaining land for future timber production and (where suitable) current timber production - the orientation was the same, even if the outcome at the time was not production but maintenance of reserves. Certainly, there is little in the early history of the Forest Service that would indicate that the agency was not producing timber because it was concerned about impacts on other resources, such as wildlife, scenery, or recreation. See ClaRY, supra note 60, at 100-02 (the Forest Service before World War II proposed use of its lands for non-timber purposes so long as those uses did not conflict with future use of land for timber production); LANGSTON, supra note 57, at 110, 112, 158-59, 177-78, chs. 56 (providing evidence from Blue Mountains in eastern Oregon and Washington in 1920s that Forest Service prioritized converting natural forests to managed forests, and dramatically increased timber sales accordingly); Nelson, supra note 58, at 41 (noting that the Forest Service restricted timber production before World War II out of a desire to avoid competition with private timber production and to preserve supplies for the future when private lands were exhausted); WILKINSON, supra note 57, at 131, 135 (stating Forest Service did not cut extensively pre-World War II due to both lack of demand and agency position that it should retain timber for future use once private lands were exhausted); Huffman, supra note 72, at 275 ("Although some timber was regularly harvested from national forest lands, the timber under [Forest Service] control had been managed primarily as a reserve against future needs."); see also Ashley L. Schiff, Innovation and Administrative Decision Making: The Conservation of Land Resources, 11 AdmIN. ScI. Q. 1, 23 (1966) (noting that the Forest Service saw its goal in protecting trees as preventing future timber scarcity).

${ }^{92}$ For instance, until 2000 the Forest Service had for many years operated under planning regulations that required the agency to explicitly set and abide by specific quantitative targets and ceilings for timber production, but left other factors under much vaguer, more qualitative standards. Compare 36 C.F.R. $\$ 219.16$ (2000) (requiring plans to set an "allowable sale quantity" for timber production), with id. $\S 219.19$ (requiring management plans to "maintain viable populations of existing native and desired non-native vertebrate species"), and id. $\S 219.23$ (requiring plan measures "to minimize risk of flood loss, to restore and preserve floodplain values, and to protect wetlands"), and id. $\$ 219.24$ (requiring plans to "provide for the identification, protection, interpretation, and management of significant cultural resources"); see also Select Comm. of the Univ. of Mont., A University View of the Forest Ser vice, S. Doc. 91-115, at 14 (1970) (describing Forest Service as a "federal agency which measures success primarily by the quantity of timber produced weekly, monthly and annually"); OFFICE OF TECH. Assessment, supra note 68, at 17-18 (stating that ease with which timber production can be measured has exacerbated agency's focus on timber production); O'ToOLE, supra note 65 , at 53-54 (noting importance of timber quotas in controlling Forest Service planning process); WILKINSON, supra note 57, at 24, 168 (noting dominance of timber quotas in determining Forest Service decision making); Arnold W. Bolle, The Bitterroot Revisited: A University Re-View of the Forest Service, 10 PuB. LAND L. REv. 1, 17 (1989) (claiming that fundamental problem with Forest Service in the 1980s was that "the Forest Service is saddled with an annual output goal for timber that makes sound management of our national forests impossible.").

${ }_{93}^{3}$ See supra notes 39-46 and accompanying text; see also V. Alaric Sample, The IMpact of the Federal Budget Process on National Forest Planning 188 (1990) (noting most non-commodity uses on the national forests are difficult to measure quantitatively). As another example, measuring the amount by which good timber management improves water quality and quantity is a much more difficult task than simply measuring water quality and quantity directly. See, e.g., Ashley L. Schiff, Fire and Water: Scientific Heresy in the Forest SERVICE 116-63 (1962) (noting long debates within Forest Service and with other agencies as to role that forests played in water quality and quantity protection). 
employees. ${ }^{94}$ Given the large number of goals that are difficult or impossible to measure, and the need to provide incentives and rewards to employees, it is understandable that the Service ended up focusing on timber production in its internal review processes. ${ }^{95}$

A third explanation is that the new profession of forestry (which Pinchot himself had played a major role in creating $)^{96}$ was oriented at the time toward timber production and provided the overwhelming majority of the new hires for the Forest Service. ${ }^{97}$ That professional orientation, as predicted by the theoretical literature, provided a relatively straightforward goal and standard by which performance of foresters could be measured - how well they managed timber stands for present and future production. ${ }^{98}$ It also provided a clear mission for the Service that aligned well with the preferences of highly trained professionals who might otherwise have pursued more renumerative jobs in private industry. ${ }^{99}$

There are, of course, other reasons for the Forest Service's focus on timber production, reasons that go beyond the focus of this Article on the problems of multiple-goal agencies subject to a single principal. Some of those problems arise from the existence of multiple principals - for instance, members of Congress and high-level executive officials regularly pressured the Service to "get the cut out" to benefit the timber industry or timber-reliant communities, even at the expense of other goals that might have benefitted the public at large or other members of Congress or other

${ }^{94}$ See, e.g., Michael Frome, The Forest Service $48-49$ (2d ed. 1984) (noting importance of hard timber quota numbers for agency and personnel evaluation); HIRT, supra note 57, at 223, 282 (noting that the Forest Service used timber production quotas to evaluate the performance of field personnel, and discussing internal survey data of Forest Service employees showing widespread belief that timber quotas are among most rewarded values within agency); YAFFEE, supra note 2, at 4 (noting that Forest Service employees were judged by their ability to "get the cut out").

${ }_{95}$ See supra notes 47-50 and accompanying text.

${ }^{96}$ See Dana \& FaIRFaX, supra note 54, at 84 (stating that if a "single date were to be selected for the birth of the profession" of forestry, "it might well be November 30, 1900, when a group of foresters met in Pinchot's office to organize the Society of American Foresters"). See generally Char Miller, Gifford Pinchot and the Making of Modern EN. VIRONMENTALISM (2001) (providing detailed history of Pinchot's creation of the modern forestry profession in United States); Huffman, supra note 72, at 251-52 (providing brief summary of same topic).

${ }^{97}$ See, e.g., DANA \& FAIrfax, supra note 54, at 53-54, 80, 131 (noting that American forestry profession has historically focused on maximizing amount of land that is actively managed for timber growth and production); HIRT, supra note 57, at xxxvii, 59-60, 136 (stating that Forest Service in post-World War II period was dominated by forestry professionals); WILKINSON, supra note 57, at 168-69 (noting importance of foresters in determining culture and goals of agency and emphasis on timber production); see also KAUFMAN, supra note 74, at 166.

${ }^{98}$ See, e.g., Select Comm. Of the Univ. of Mont., A University View of the Forest SERVICE, S. Doc. 91-115, at 22 (1970) ("The core of forestry professionalism, the central tenent [sic] of professional dogma, is sustained yield timber management."); HIRT, supra note 57 , at $\mathrm{xx}$ (stating that forestry professionals before and after World War II were almost exclusively focused on timber production); KLYZA, supra note 58, at 85 (noting hostility of Society of American Foresters toward creation of wilderness areas in 1960s).

${ }_{99}^{9}$ See supra notes $47-50$ and accompanying text. 
executive agencies. ${ }^{100}$ The appropriations process, in particular, has historically been a source of pressure from a subset of Congress (members of the appropriations subcommittees that fund the Forest Service, traditionally drawn disproportionately from timber-producing states and districts) on the Forest Service to maintain or increase timber production. ${ }^{101}$ And even separate from the appropriations process, there are budgetary incentives for the Forest Service to conduct timber operations. ${ }^{102}$ These factors can be understood to alter the instructions given by Congress in the substantive statutes (organic acts, MUSYA, NFMA) to increase the emphasis on the goal of timber production. On the other hand, Congress never eliminated the other goals of recreation or wildlife, and there are serious problems with considering the appropriations process as the true voice of Congress. ${ }^{103}$

Neither is the history of the Forest Service a monolithic one. Even before passage of MUSYA, groups within the Forest Service were pushing for more consideration of other goals besides timber management, including wilderness and recreation. ${ }^{104}$ Other interests such as grazing certainly had an

${ }^{100}$ See, e.g., HIRT, supra note 57, at 62, 107, 236, 272 (noting examples of congressional and presidential pressure on Forest Service). The Reagan Administration placed significant pressure on the Forest Service to increase timber production through political appointees in the Department of Agriculture and through the budget process. See id. at 266-67, 270.

${ }^{101}$ WILKINSON, supra note 57, at 170-71 (noting importance of congressional pressure in determining Forest Service timber cut levels); YAFFEE, supra note 2, at 117, 242 (noting pressure on the Forest Service from Congress to cut in Northwest, particularly from the appropriations subcommittees); Stark Ackerman, Observations on the Transformation of the Forest Service: The Effects of the National Environmental Policy Act on U.S. Forest Service Decision Making, 20 EnVTL. L. 703, 726 (1990); Elise S. Jones \& Will Callaway, Neutral Bystander, Intrusive Micromanager, or Useful Catalyst?: The Role of Congress in Effecting Change Within the Forest Service, 23 PoL'Y STUD. J. 337, 342-43 (1995) (providing evidence of congressional pressure on the Forest Service to increase timber production).

${ }^{102}$ A significant portion of the Forest Service's budget has historically been derived from and based on timber sales. See Bolle, supra note 92, at 5 . Despite recent statutory changes, that is still true to at least some extent. See, e.g., Earth Island Inst. v. U.S. Forest Serv., 351 F.3d 1291, 1309-10 (9th Cir. 2003) (Noonan, J., concurring) (noting that "money received from timber sales by the Forest Service is, by statute, to be deposited in a special fund to be used for construction of 'needed roads' by the Forest Service and to cover 'the cost for Forest Service sale preparation and supervision of the harvesting of such timber' " and accordingly without timber sales "Forest Service jobs would be lost" (citing 16 U.S.C. \$ 472a(h))). Accordingly, changes in the timber program can have significant impacts on the size of the Forest Service's budget. See SAMPLE, supra note 93, at 21-22, 38 tbl.2.4 (collecting data showing that in late 1970s and 1980s Congress disproportionately funded timber sales more than any other program area run by Forest Service); Brunson \& Kennedy, supra note 58, at 152 (noting Forest Service "timber harvests subsidize nonpriced forest uses").

${ }^{103}$ For instance, earmarks or instructions in appropriations committee reports as to timber production levels effectively cannot be altered by Congress as a whole when it considers the appropriations legislation. Congress can amend the text of the appropriations bill, but not the committee report where the timber quotas might actually have been specified. See supra note 54.

${ }^{104}$ See ClARY, supra note 60, at 100-01, 150 (noting that Forest Service beginning in 1920 s and 1930s began to embrace concept of "multiple-use" on its lands through set-asides of primitive areas and active management for wildlife and recreation); KLYZA, supra note 58, at 22 (describing limited but increasing efforts by Forest Service to create primitive areas that restricted development and exploitation in the 1920s and 1930s). However, the agency generally would only set aside lands for these different purposes where lands were not suitable for 
important influence within the Service's decision-making process. ${ }^{105}$ The Service itself, after an initial hesitation, supported the passage of MUSYA because it would increase the Service's discretionary powers. ${ }^{106}$ And after the enactment of MUSYA as well as NFMA, the Forest Service did indeed begin to consider other goals besides timber production to a greater and greater extent, particularly in the later 1980s and 1990s. ${ }^{107}$ Part of that more recent change was a result of diversification of the workforce of the Forest Service that, by the 1990s, had led to fundamental changes in attitudes toward environmental protection within the Service. ${ }^{108}$

Nonetheless, it took the Forest Service a number of years after the passage of both MUSYA and NFMA to change its status as an organization strongly oriented toward timber production. ${ }^{109}$ And a key component of that delay was tardiness in developing information about goals other than timber production. This Article does not intend for this conclusion to be a critique of the Forest Service. For many years, the Service's focus on timber production was a faithful implementation of one of the primary goals that Congress had set out for the Service. Whatever delay the Forest Service might have had in changing its priorities in the wake of the passage of MUSYA and NFMA, this Article does not suggest this was the result of bad faith or incompetence on the part of anyone in the Service. The fact is that there are

large-scale timber production. See ClaRY, supra note 60, at 151 (describing Forest Service official stating that "[t]imber production is given priority over other uses on the most important areas of commercial forest land, with recreation, livestock grazing, and wildlife being integrated as fully as possible without undue interference with the dominant use"). See generally Charles F. Wilkinson \& H. Michael Anderson, Land and Resource Planning in the National Forests, 64 OR. L. Rev. 1, 334-44 (1985) (discussing history of Forest Service's wilderness preservation policies through 1960s).

${ }^{105}$ See, e.g., Debra L. Donahue, The Western Range Revisited 69-70 (1999) (arguing that Forest Service has been susceptible to pressure from grazers); William VoIGT, JR., Public Grazing LaNDS (1976) (describing pressures that ranchers have been able to bring on Forest Service to restrict its ability to limit grazing on national forests).

${ }^{106}$ See Clary, supra note 60, at 154-56 (noting initial hesitation by Forest Service when environmental groups proposed concept of a multiple-use bill, followed by acceptance); HiRT, supra note 57, at 175-77 (same); see also DANA \& FAIRFAX, supra note 54, at 200-02 (noting that Forest Service "wrote the bill and lobbied for it"); Dennis C. Le Master, Decade of Change: The Remaking of Forest Service Statutory Authority During the 1970s, at 4-5 (1984) (stating that Forest Service wanted passage of MUSYA in order to increase its discretionary power); Nelson, supra note 58 , at 23, 454-55 (same).

${ }^{107}$ See, e.g., Sax \& Keiter, supra note 58, at 227-29 (noting that Forest Service, in managing one national forest (Flathead National Forest) in 1980s, was more willing to limit development in order to protect values of neighboring Glacier National Park).

${ }^{108}$ See Greg Brown \& Charles C. Harris, The Implications of Work Force Diversification in the U.S. Forest Service, 25 ADMIN. \& Soc'Y 85 (1993) (providing survey data showing that Forest Service employees that are more diverse in terms of professional background and gender are more likely to have perspectives that favor environmental protection); Greg Brown \& Charles C. Harris, The United States Forest Service: Changing of the Guard, 32 NAT. RESOURCES J. 449, 464-65 (1992) (same). This change in workforce in the agency was partly the result of internal personnel changes, but also likely connected to changes in the agency's legal mandates for multiple-use under MUSYA and FLPMA, as well as the ESA and NEPA. For a discussion of the importance of agency cultural changes in solving the multiple-goal problem, see infra Part II.C.

${ }^{109}$ See supra notes 57-68 and accompanying text. 
limits to the extent to which agencies will be able to quickly change their orientation toward particular goals and, most importantly for this inquiry, develop the information about performance on new goals in a short period of time. In other words, agencies are constrained in their ability to solve the problems of multiple goals on their own. The key question is to what extent institutional design mechanisms or legal constraints imposed from the outside can help agencies solve this problem.

\section{Is There a Problem?}

Before turning to solutions, it is important to address a more fundamental question: Is there even a problem with multiple-goal agencies? The case study of the Forest Service does not just show an agency that was slow to respond to changes in congressional instructions in MUSYA and NFMA. It also shows that Congress (or portions of Congress) might have acquiesced in the Service's hesitation to change its focus to include the newly identified goals and develop information about performance on those goals. In other words, isn't it possible that a principal might seek to maintain overperformance on some goals and underperformance on others through the incentives and supervision that the principal provides to the agency? For instance, congressional requests for higher timber sales in the appropriations process and maintenance of budgetary systems that encouraged timber production could be considered to be just this kind of support for overperformance on timber production by the Forest Service. ${ }^{110}$

If it is true that Congress as principal is acquiescing in an agency's overperformance on primary goals and underperformance on secondary goals, then it would seem that there is no "problem" for the multiple-goal agency. The agency is, in fact, following the instructions of its principal. But as the examples provided throughout this Article demonstrate, there are many times where Congress is not satisfied with the performance of its agents on multiple goals, and has taken steps to try to correct those shortcomings. The goal of this Article is to analyze the various tools that a principal such as Congress may utilize if it does seek to change an agency's allocation of its resources across multiple goals, given the structural problems discussed in Part I.

${ }^{110}$ Despite this evidence of congressional (as well as presidential) pressure on the Forest Service to maintain timber production, there is also abundant evidence laid out in Part 1.C supra that there was a dynamic within the agency itself that prevented it from developing information about its performance on other goals such as wildlife. The professional orientation of Forest Service employees, the strong acculturation of new employees, and employee perceptions as to the attitudes and perspectives of their colleagues and the agency as a whole, all point to an endogenous source for the agency's inability to collect information concerning its performance on other goals besides timber production. See supra notes 70-88 and accompanying text. Many other observers have explicitly connected the change in Forest Service performance and culture to outside pressure due to ESA litigation, and contrasted those changes with the earlier Forest Service's strong focus on timber production. See infra notes 223-226 and accompanying text. 


\section{III. "Intra-Agency" Solutions: Reclaiming Power, Separating Functions, and Changing Internal Agency Cultures}

To this point, this Article has established that multiple-goal agencies are widely distributed in the government, that theory would indicate that multiple-goal agencies are subject to specific kinds of pressures in how they operate, that those pressures have (at least in some high-profile examples) resulted in systematic trends in how agencies address different goals, and that these agencies will face substantial difficulties in solving these problems on their own. This section now turns to explore possible organizational and legal design solutions.

The description of the problem helps to define the range of solutions. If a principal wishes to address the multiple-goal problem and maintain the principal-agent relationship, it will have to deal with it either by eliminating the existence of two conflicting goals within one agency (so that the conflict between the more measurable and less measurable goal will not result in overemphasis on the former and underemphasis on the latter); or, by somehow changing or ameliorating the mission orientation of an agency that might interfere with its ability to develop better ways to measure goals. These are the two options that make up what this Article defines as the "functional" range of solutions to the multiple-goal agency problem.

In order to achieve those "functional" goals, a principal might choose between two main "structural" strategies: either directly changing the structure of the decision-making agency ("intra-agency" solutions) or using the interaction of multiple agencies to change the outcomes produced by the decision-making agency ("inter-agency interaction" solutions). Both "intraagency" and "inter-agency" strategies might address either one of the functional goals (splitting goals or encouraging innovation), and some may be hybrids that address both functional goals. ${ }^{111}$

With these principles in mind, a diverse range of seemingly disparate legal and institutional design choices can now be seen as part of a coherent whole. From the division of agencies to the creation of inter-agency monitoring and regulatory systems, a wide range of tools that have been used in administrative law in general, and environmental law in particular, can be understood as efforts to address the multiple-goal agency problem. The remainder of this Article seeks to identify the major categories of methods used by various principals to address the multiple-goal agency problem, whether consciously or not. While this overview is not completely comprehensive, it is sufficient to flesh out the typology developed above of the range of solutions that do or might exist, and to provide a lens by which the effectiveness of various legal and institutional design choices might be understood.

111 See Figure 1 infra for an overview. 
This Article's survey of these solutions, and its overall typology, is organized according to the "institutional structure" typology: Whether the solution attempts to deal with the multiple-goal agency problem by focusing on the agency itself ("intra-agency" solutions), or, alternatively, by relying on "inter-agency interaction." Part II explores the various "intra-agency" strategies: de-delegation of powers from an agent, splitting the agency up to focus on separate tasks, or changing the internal culture of the agency to address the underperformance on secondary goals. Part III then explores solutions that depend on the interaction between different agencies.

\section{A. Reclaiming Power: Principal Retaking Important Decisions That Involve Fundamental Tradeoffs}

Before tackling the various strategies to change or improve the principal-agency relationship for multiple-goal agencies, this Article first explores what might seem an obvious and easy possibility - simply to eliminate the principal-agent relationship. The principal can retake important decisionmaking power in general, or in particular circumstances where the principal is concerned about the agent's inability to properly balance multiple goals. ${ }^{112}$ Note that in choosing this solution, to a certain extent the principal is giving up on the agent's ability to properly make major decisions; instead of either separating goals or attempting to change the agency's mission, the principal is essentially discarding delegation as an option.

An important example of this is the passage of the Wilderness Act by Congress in 1964. For decades, the Forest Service had been designating areas within its jurisdiction that were off-limits to intense development or commercial logging, areas variously called "primitive areas" or "wilderness areas." 113 However, designation of such areas necessarily involved a tradeoff between the goal of protecting lands from development and the goal of producing large quantities of commercial timber. For a variety of reasons discussed above, outside environmental groups and some members of Congress questioned whether the Forest Service was too focused on timber production instead of adequately striking the balance between these two goals. ${ }^{114}$ Indeed, there was evidence that as timber production became more economically valuable, the Forest Service was increasingly re-designating areas that had been previously made off-limits to commercial timbering. ${ }^{115}$

Partly in response to this dynamic, Congress passed the Wilderness Act, which explicitly withdrew the power from the various land-management agencies (not just the Forest Service) to either create or eliminate wilderness

112 Kevin Siqueira, Common and Exclusive Agencies and Partial Delegation, 23 J.L. ECON. \& ORG. 141 (2007) (proposing this solution).

${ }^{113}$ See Wilkinson \& Anderson, supra note 104, at 334-44.

114 See supra notes 58,68 and accompanying text.

115 See supra note 76. 
areas, instead reserving that power exclusively for Congress. ${ }^{116}$ Thus, for one particular decision fraught with controversy over fundamental tradeoffs between competing goals, Congress as principal took it upon itself to make the final decision.

Of course, this solution is only of limited usefulness in most contexts of multiple-goal agencies. Reserving the decision to the principal (even when informed by recommendations and advice from the agent) is a costly proposition for the principal. For instance, changes to the wilderness system require the passage of an act of Congress, which has resulted in dozens of statutes to add units to the system or alter their management requirements. ${ }^{117}$ Instead, Congress usually creates an agent to undertake particular tasks, precisely because those tasks are too time-consuming or otherwise costly for Congress to feasibly do the work itself.

\section{B. Separating Functions: The Difficulty of Separating Interconnected and Interrelated Goals}

As noted above, one of the possible "functional" goals of solutions that seek to address the multiple-goal agency problem is to split up conflicting goals. The easiest way to do this is simply to separate the conflicting goals into different agencies - Goal A goes to new Agency 1, Goal B goes to new Agency 2. This solution has been called for by a range of proponents and is the most frequently cited solution in the economics and political science literature. ${ }^{118}$ It is also a solution that has been adopted historically on a number of occasions by the federal government. For instance, in response to claims that the development/research and safety functions of the old Atomic Energy Commission ("AEC") resulted in conflicts that made it a poor safety regulator, Congress split the AEC, assigning safety issues to the Nuclear Regulatory Commission ("NRC") and placing the development and research components into what became the Department of Energy. ${ }^{119}$ More recently, the Immigration and Naturalization Service ("INS") was charged with both providing service for immigrants and visitors to aid in the tourism

${ }^{116}$ See 16 U.S.C. $\$ 1131$ (a) (2000) ("[N]o Federal lands shall be designated as "wilderness areas" except as provided for in this chapter or by a subsequent Act."); id. $\S 1132$ (reserving to Congress the power to increase, decrease, create, or eliminate units from the wilderness system).

${ }^{117}$ See 16 U.S.C.A. $\$ 1132$ (West 2008) (listing all the various acts passed by Congress to create wilderness areas since the passage of the Wilderness Act).

${ }_{118}$ See Dewatripont et al., supra note 30, at 876; Dixit, supra note 18, at 723 ("Mutually substitute activities are better carried out in separate agencies ...."); Siqueira, supra note 112, at 141-43 (noting that splitting up agencies is one option to deal with conflicting goals); Ting, supra note 24, at 365 (arguing that many unusual allocations of tasks among different government agencies can be explained by the need to split up tasks that are conflicting); see also WILSON, supra note 17, at 371 (stating that agencies with strong missions may give autonomy to sub-units that perform secondary or unrelated tasks).

${ }^{119}$ Energy Reorganization Act of 1974, Pub. L. No. 93-438, 88 Stat. 1233; see also ALICE L. Buck, U.S. Dep't of Energy, A History of the Atomic Energy Commission 8 (1983) (describing history of conflict). 
and naturalization process and enforcing immigration laws against non-citizens. Again, claims that the two goals fundamentally conflicted and interfered with each other led to the split of the agency into three parts: U.S. Citizenship and Immigration Services ("CIS," handling administration of immigration services); U.S. Immigration and Customs Enforcement ("ICE," handling investigation and enforcement); and U.S. Customs and Border Protection ("CBP," handling border patrol and inspection). ${ }^{120}$

There can be good reasons for a split. It can eliminate the potential conflicts between goals that are substitutes, allowing each individual agency to focus on the particular goals that it is assigned. Moreover, this option makes a lot of sense if a single, overriding mission is necessary for public agencies to motivate employees successfully ${ }^{121}$ or to compensate for goals that are inherently difficult to measure. ${ }^{122}$ Indeed, for the latter case, where distortions of the incentives of the multiple-goal agency are inevitable, splitting an agency may allow for the separation of the difficult-to-measure goals so that a new agency can develop a core mission focusing on those goals. ${ }^{123}$

But the role for agency splitting as a solution to the problem of the multiple-goal agency is likely quite limited. First, even newly split agencies will still have multiple goals because they are still required to comply with many of the mandates that cut across all federal government agencies, such as NEPA and freedom of information - although the interaction of those multiple goals may be much less problematic. But more importantly, there are many situations where even goals that are specific to a particular agency cannot be split up because they are interdependent and interrelated. ${ }^{124}$ For instance, in the public lands management context, it would be inefficient indeed, just plain silly - to have one agency in charge of logging, another agency in charge of mining, another in charge of grazing, and another in

${ }^{120}$ Homeland Security Act of 2002, Pub. L. No. 107-296, \$\$ 441-442, 451, 471, 116 Stat. 2135, 2193-94, 2195-97, 2205 (codified in scattered sections of U.S.C.); see also Eric Schmitt, Vote in House Strongly Backs an End to I.N.S., N.Y. Times, April 26, 2002, at Al (describing vote to split INS into two separate bureaus).

${ }^{121}$ See supra note 47 and accompanying text; WiLson, supra note 17, at 158; Timothy Besley \& Maitreesh Ghatak, Incentives, Choice, and Accountability in the Provision of Public Services, 19 OXFORd Rev. ECON. POL'Y 235, 240-41, 243-44 (2003) (relying in part on argument that public sector employees accept lower monetary rewards in return for focusing on particular missions that provide non-monetary benefits); Besley \& Ghatak, supra note 47 , at 617 (same); Dewatripont et al., supra note 30, at 875 (arguing that government agencies perform more effectively and are more successful when they focus on core missions); Dewatripont et al., supra note 48, at 200-02, 206-14 (arguing that multiple missions impair agency incentives); Koen Verhoest, Effects of Autonomy, Performance Contracting, and Competition on the Performance of a Public Agency, 33 PoL'y STud. J. 235, 239 (2005).

${ }^{122}$ See supra notes $48-50$ and accompanying text.

${ }^{123}$ Core missions also might allow an agency to focus on the hiring and training of specific professional staff, and perhaps allow the development of additional expertise not otherwise obtainable.

${ }^{124}$ Holmstrom \& Milgrom, supra note 26, at 49 ("[T]asks like maintaining quality and producing output cannot always be separated."). Environmental goals may be a particularly important example of this class. See Robert G. Chambers \& John Quiggin, Non-Point-Source Pollution Regulation as a Multi-Task Principal-Agent Problem, 59 J. PuB. Econ. 95,96 (1996). 
charge of recreation, all for the same geographic area. Space is finite and land often can be used for only one goal, or sometimes for a few conflicting goals. Accordingly, coordination would be required among the different agencies at least to ensure that their projects did not spatially conflict. ${ }^{125}$ The result would be higher transaction costs for the coordination efforts, or the creation of yet another agency to coordinate the various disputes. And of course the coordinating agency would itself be tasked with a multiple-goal problem - trying to reconcile the myriad goals of the various specialized agencies.

\section{Changing Internal Agency Cultures: Resistance to Change and the Inevitable Necessity of a Primary Goal}

Instead of splitting conflicting goals, a reformer might seek to change the internal culture of the agency so that its mission no longer interferes with the innovation needed to develop improved measurements of "secondary" goals. There are a range of methods available to accomplish this: changing the internal incentives structure of the agency by increasing the incentives provided for less measurable or otherwise secondary goals; working directly to change the mission of the agency through political and bureaucratic pressure; imposing procedures on the agency that require it explicitly to consider "secondary" goals in its decision-making process; or hiring personnel in the agency who are professionally or personally committed to advancing one or more of the "secondary" goals.

One striking example of these types of efforts has been NEPA. ${ }^{126}$ Enacted on January 1, 1970, NEPA requires all federal agencies, prior to conducting any "major Federal actions [that] significantly affect[] the quality of the human environment," to prepare a detailed statement about the potential impacts of that action on the environment (the Environmental Impact Statement, or "EIS"). ${ }^{127}$ NEPA has had a profound effect on the decisionmaking procedures of most government agencies - as of 2002, various government agencies produce approximately 500 EISs each year, as well as approximately 50,000 less detailed environmental assessments ("EAs"). ${ }^{128}$

A major goal of NEPA was to force agencies that formerly had focused too heavily on primary missions such as highway construction, water-project development, or the extraction of natural resources, to also consider the impacts of their actions on the environment. ${ }^{129}$ The main tool in NEPA to force

${ }^{125}$ Of course, there are many other ways projects can conflict besides simply requiring the same geographic coordinates. Pollution or effluent from one project might exclude another project from a nearby location, or the exploitation of one resource in one location might fundamentally change or eliminate that resource in another location.

12642 U.S.C. $\$ \S 4321-4347$ (2000).

${ }^{127}$ Id. $\$ 4332(\mathrm{C})$.

${ }^{128}$ Bradley C. Karkkainen, Toward a Smarter NEPA: Monitoring and Managing Government's Environmental Performance, 102 Colum. L. Rev. 903, 909-10 (2002).

129 See 115 Cong. REC. 29,053 (1969) (statement of Sen. Muskie) (stating, during debate on NEPA, that development "agencies have always emphasized their primary responsibilities 
that change in perspective was the imposition of the EIS requirement and related NEPA procedures. ${ }^{130}$

There are a number of ways in which NEPA procedures might work to change internal agency decision-making. First, NEPA may directly inspire an agency to shed its mission orientation and discover information through the EIS or other procedural processes that allows it to accomplish its primary objectives with less conflict with the secondary goal of environmental protection. To achieve this result, NEPA's requirements that the agency produce information documents must, in turn, force an agency to overcome internal resistance (because of history or mission) to analyzing and developing information about "secondary" goals, and as a result to discover new solutions (or implement pre-existing ones) to improve the measurement of difficult-toobserve goals. The likelihood of achieving these types of gains depends on the likelihood that prior to NEPA an agency's culture or mission was leading it to ignore "inefficiencies" in its operations or projects that were causing unnecessary environmental damage. ${ }^{131}$

making environmental considerations secondary in their view" and that NEPA was required to change this bias); William L. Andreen, In Pursuit of NEPA's Promise: The Role of Executive Oversight in the Implementation of Environmental Policy, 64 IND. L.J. 205, 205 (1989) ("Frustrated by the insensitivity of many federal agencies to the environmental consequences of their actions, Congress enacted . . NEPA.”); Lynton K. Caldwell, Environmental Impact Analysis (EIA): Origins, Evolution and Future Directions, 6 Impact Assessment Bull. 75, 77 (1988) ("The objective of NEPA's drafters [was to create] a device to transform and reorient the values and assumptions entering into the decisions of the federal agencies.") (statement by Professor Caldwell, an academic heavily involved in drafting of NEPA); Ray Clark, NEPA: The Rational Approach to Change, in Environmental Policy and NEPA: Past, Present, AND FUTURE 15, 17 (Ray Clark \& Larry Canter eds., 1997) (describing NEPA as a response to "a growing recognition that the narrow, mission-oriented approach of federal agencies to programs and projects" was harming the environment); Paul J. Culhane, NEPA's Impacts on Federal Agencies, Anticipated and Unanticipated, 20 ENVTL. L. 681, 684-85 (1990) (characterizing NEPA as in part a response to "agencies [that] pursued narrow missions single-mindedly"); Daniel A. Dreyfus \& Helen M. Ingram, The National Environmental Policy Act: A View of Intent and Practice, 16 NAT. Resources J. 243, 254 (1976) (describing NEPA as an "action-forcing mechanism" that places "[e]mphasis . . . upon environmental concerns" as "a necessary means of instilling the new policy into an uncongenial decisionmaking process in which ... f federal agencies were wedded to their own missions and to economic efficiency"); Matthew J. Lindstrom, Procedures Without Purpose: The Withering Away of the National Environmental Policy Act's Substantive Law, 20 J. Land Resources \& ENvTL. L. 245,249 (2000) ("The framers of NEPA intended to substantively redirect the goals and policy decisions generated within federal agencies so that, collectively, the nation would recognize the importance of environmental assets along with other national interests.").

${ }_{130}$ See, e.g., S. Rep. No. 91-296, at 9 (1969); Serge Taylor, Making Bureaucracies THINK 7 (1984) (noting that NEPA drafters "tried to change agency policies indirectly by requiring a different type of information to enter the decision-making process"); Dreyfus \& Ingram, supra note 129, at 251-53. The courts have interpreted NEPA as not containing any substantive requirements. See, e.g., Robertson v. Methow Valley Citizens Council, 490 U.S. 332,350 (1989) ("[I]t is now well settled that NEPA itself does not mandate particular results, but simply prescribes the necessary process.").

${ }_{131}$ See TAYLOR, supra note 130, at 157-58 (noting that the EIS process tends to produce environmental benefits where they can be had "with the least effect on the achievement of other project goals"). Such an outcome assumes that the agency's mission orientation and reluctance to develop better measures on conflicting goals are so strong that the agency refuses to develop information about and implement not only alternatives favoring secondary goals 
Second, NEPA might result in better supervision of the agency by the principal. By requiring agencies to overcome their mission orientation and to innovate in a way that allows for improved information relevant to "secondary" goals such as preservation of the environment, those "secondary" goals will become more relevant for the principals. The principals in turn may use that information to hold the agency accountable for underperformance on important secondary goals such as environmental protection. ${ }^{132}$ Over time, this may produce a fundamental change in how the agency balances these otherwise conflicting goals.

Third, and arguably most importantly, the requirement that agencies conduct NEPA analyses may force the agency to hire staff who are expert at producing those analyses. Those staff are likely to be professionally trained in fields such as biology, toxicology, public health, pollution control, and other areas. Given that professional training, these staff may have very different professional orientations and non-monetary goals than the traditional staff of the agency. ${ }^{133}$ With time, these new environmentally minded staffers may change the internal culture of the agency in a way that causes the agency to skew a little less toward its primary mission - either because less of a conflict is perceived between the two goals, or because the differentiation between "primary" and "secondary" goals is moderated or (in the extreme case) even eliminated. ${ }^{134}$ In particular, this option can help overcome the problem of historical inertia of an agency that has suddenly been asked

over the agency's primary mission, but also alternatives having minimal impact on that primary mission. While that outcome would be irrational, irrational agency performance is not a farfetched possibility. See generally Jeffrey J. Rachlinski \& Cynthia R. Farina, Cognitive Psychology and Optimal Government Design, 87 CoRnell L. Rev. 549 (2002) (discussing ways in which agencies may be limited in their ability to pursue optimal outcomes).

${ }^{132}$ See TAYLOR, supra note 130 , at 18-21, 30, 37, 131, 160 (noting how providing analysis to groups outside agency can result in mobilization and political pressure to challenge agency decisions, and arguing that NEPA has helped accomplish this in the environmental context).

${ }^{133}$ There is good evidence that this is precisely what happened with a number of federal agencies after the enactment of NEPA. See id. at 103, 125-26 (noting increase in environmental specialists in Forest Service and Army Corps of Engineers ("the Corps") in wake of NEPA and observing that NEPA "accelerated" this increase); id. at 252 (noting that "[t]he EIS process has been most successful in installing in the federal agencies a group favoring the precarious [environmental] value"); id. at 301, 305-06 (emphasizing importance of internal environmental experts in changing agency decision making); RICHARD N.L. ANDrEws, ENvironmental Policy and Administrative Change 76-77 (1976) (citing evidence that the Corps expanded its environmental staff in response to NEPA requirements); DANIEL A. Mazmanian \& Jeanne Nienaber, Can Organizations Change? Environmental Protection, Citizen Participation, and the Corps of Engineers 42-45, 47, 56 (1979) (noting hiring of non-engineers in environmental compliance units created for NEPA work); see also KLYZA, supra note 58, at 150 (noting increase in diversity of Forest Service employees since 1980 s, resulting in changes in agency culture in 1990s); Culhane, supra note 129, at 690-91 (noting evidence that NEPA led to hiring of more diverse professional staffs in at least some agencies); Michael Herz, Parallel Universes: NEPA Lessons for the New Property, 93 CoLUM. L. REv. 1668, 1711-12 (1993) (summarizing evidence that the Corps added new environmental staff to respond to NEPA); see supra note 108 and accompanying text.

${ }^{134}$ For example, after the enactment of NEPA and other environmental statutes in the late 1960 s and early 1970s, the Corps responded in part by expanding its mission to include environmental restoration projects that would have less conflict with environmental goals. See CLARKE \& McCool, supra note 58, at 4-5, 42, 44-47 (noting that the Corps was among the 
to expand the range of goals that it should consider. The end result is an agency more willing to develop innovative ways to measure its secondary goals, even if some conflict with its primary mission would result, precisely because the organization as an institution is less wedded to that mission. Note that this change does not depend on the direct impacts of the NEPA information-production requirements - it is not the environmental review documents, but instead the hiring of new staff to perform those environmental reviews, that forces the agency to change its mission. ${ }^{135}$

One important question is how effective NEPA has been in using these various methods to force changes in agency consideration of environmental values. Certainly, the prevalence of "win-win" solutions would be a success, though it is questionable how many of these exist and how great a difference they might make. The staff that are hired as a result of NEPA may be sequestered in organizational cul-de-sacs with little influence over the planning and prioritization decisions of the agency. ${ }^{136}$ As a result, they may be relegated to tinkering at the margins of destructive projects by finding the few changes that would improve environmental quality without harming the underlying project goals and by providing justifications for decisions already made. ${ }^{137}$ In addition, many agencies may contract out some or all of their EIS and EA preparation duties, such that even the benefits of having staff with different perspectives in the agency are lost. ${ }^{38}$ Accord-

agencies that most quickly responded to enactment of NEPA, and that around same time the Corps also began to expand its mission to include restoration projects).

${ }^{135} \mathrm{It}$ is possible that agency mission reorientation might occur as a result of retasking existing agency personnel to work on environmental review processes and documents. However, there may be significant resistance because of the professional orientation of employees such as engineers. See supra notes $47,51,79-80,96-98$ and accompanying text (discussing the inertia that may be created by the education and culture of a professional group).

${ }^{136}$ See MAZMANiAN \& NiENABER, supra note 133 , at 47-51, 56-58 (stating that environmental units in the Corps often were isolated into organizational sub-units that had limited or no impact on overall agency priorities and were primarily intended to ensure that development projects succeeded); Karkkainen, supra note 128, at 924 (noting risk that NEPA staff may be placed "outside the agency's decisionmaking hierarchy").

${ }^{137}$ For instance, one critique of NEPA has been that agencies only begin the preparation of an EIS once they have internally committed to a major project, and that the analysis of alternatives to the project is simply a pro forma exercise with little true meaning. See, e.g., Sally K. Fairfax, A Disaster in the Environmental Movement, 199 SCIENCE 743, 744 (1978) (arguing that EIS process is counterproductive because it arrives too late and is not fully integrated into the agency decision-making process); Bradley C. Karkkainen, Whither NEPA? 12 N.Y.U. ENVTL. L.J. 333, 346 (2004) ("Due to the time it takes to produce, the EIS will also typically arrive too late in the process to inform and influence the agency's decision."). The Council on Environmental Quality ("CEQ"), the federal agency within the White House charged with overseeing NEPA's implementation, has reached similar conclusions in its own analysis. See CEQ, The National Environmental Policy Act: A Study of Its Effectiveness After TwENTY-FIVE YeARS, at ix, 11 (1997).

${ }^{138}$ See, e.g., MAZmanian \& Nienaber, supra note 133, at 45-46 (noting that the Corps sometimes used outside consultants for NEPA compliance with minimal internal agency cultural changes in some units); Richard N.L. Andrews, The Unfinished Business of National Environmental Policy, in Environmental Policy and NEPA: Past, Present, and Future, supra note 129, at 85, 91 (stating that many EISs "are largely prepared by outside consultants as paperwork requirements rather than as an integral part of the agency's own thought pro- 
ingly, there is reason to doubt the ability of NEPA, or indeed any outside effort, to fundamentally change the culture of a multiple-goal agency. ${ }^{139}$

On the other hand, there is evidence that NEPA has resulted in the termination of projects that are environmentally destructive, and some observers of the agency decision-making process have argued that NEPA has fundamentally changed how agencies operate. ${ }^{140}$ Indeed, one agency that was historically perceived as among the most intransigent in its orientation toward development projects and in its antipathy toward environmental concerns - the Army Corps of Engineers ("the Corps") - has been praised by a number of academics for its willingness and ability to embrace NEPA and to change its decision-making process and approach as a result. ${ }^{141}$

Overall, then, the evidence about the success of NEPA is ambiguous. ${ }^{142}$ And that is unlikely to change. As one scholar has remarked, "[i]f after twenty years of EISs there is still no conclusive empirical evidence as to whether NEPA has in fact influenced agency decisions, such evidence is unlikely to appear." 143 That is probably not very surprising, since "[i]t is impossible . . . to do a controlled experiment in which NEPA is isolated from all other influences on decision-making." 144 However, some tentative conclusions about where NEPA is more or less likely to make a difference can

cess"); Karkkainen, supra note 128, at 924 n.91 (citing studies that show extensive use of consultants by some federal agencies to satisfy NEPA requirements).

${ }^{139}$ See, e.g., Richard N.L. Andrews, Agency Responses to NEPA: A Comparison and Implications, 16 NAT. Resources J. 301, 313 (1976) (concluding, after studying the Corps and Soil Conservation Service, that "few substantive changes in proposed water projects were made by either agency as a direct consequence of NEPA").

${ }^{140}$ See, e.g., Culhane, supra note 129, at 690 (concluding that NEPA has led to increase in consideration of environmental impacts in agencies); H. Paul Friesema \& Paul J. Culhane, Social Impacts, Politics and the Environmental Impact Statement Process, 16 NAT. Resources J. 339, 354-55 (1976) ("NEPA and the EIS process have been effective in bringing environmental pressures to bear on agency decisionmaking."); Herz, supra note 133, at 1702 ("Requiring consideration of environmental harms, for example ... will inescapably produce more environmentally protective decisions than would occur absent such a requirement.").

${ }^{141}$ See ANDREws, supra note 133 , at 53-54, 67-69, 89; CLARKE \& MCCOOL, supra note 58, at 23, 57.58 (identifying the Corps and Forest Service as two agencies that quickly and effectively adapted to NEPA); Mazmanian \& Nienaber, supra note 133, at 2-3 (discussing how the Corps has been one of most aggressive federal agencies in adopting NEPA); TAYLOR, supra note 130, at 95, 130 (noting integration of environmental analysis into the Corps over time and improved environmental decision making in the Corps and Forest Service). However, even these studies are somewhat equivocal in evaluating the outcomes of the changes in the Corps' procedures, and whether they have led to actual decreases in the environmental damage caused by the agency. See ANDrEws, supra note 133, at 60-65, 135 (noting superficial nature of some of the Corps's early EIS statements); TAYLOR, supra note 130, at 194-95 (questioning whether NEPA procedures ultimately changed quality of decisions made by the Corps).

${ }_{142}^{12}$ See, e.g., Allan F. Wichelman, Administrative Agency Implementation of the National Environmental Policy Act of 1969: A Conceptual Framework for Explaining Differential Response, 16 NAT. RESOURCES J. 263 (1976) (noting great differences in rates and successes of NEPA implementation across range of federal agencies).

${ }^{143}$ Herz, supra note 133, at 1704; see also Richard A. LiRofF, A NATIONAl Policy For THE ENVIRONMENT: NEPA AND ITs AFTERMATH 84-85 (1976) (noting difficulty measuring impact of NEPA); Karkkainen, supra note 128, at 911 ("How much [change NEPA has wrought on agencies] is hotly contested and remains anyone's guess.").

${ }^{144}$ Herz, supra note 133, at 1704 . 
be drawn. First, in the short run, NEPA appears to be quite effective in making relatively small-scale changes to already-made decisions that result in "win-win" outcomes. NEPA is less likely to be influential in fundamentally changing the planning, prioritization, and programmatic decision making of an agency - areas where the largest environmental benefits could be achieved, but at greatest cost to the agency's underlying mission. ${ }^{145}$

Second, NEPA has been much more effective where agencies have been under external pressure - whether from Congress, the courts, or the public - to change their decision-making process to be more environmentally sensitive. ${ }^{146}$ Indeed, one of the most important factors in whatever success NEPA has had in changing agency culture has been the fact that NEPA's procedural requirements (at least) are enforceable in court against the agency. ${ }^{147}$ This is likely because agencies have much more incentive to invest in the changes in personnel that could lead to changes in agency culture where new personnel are required to ensure that environmental reviews can satisfy judicial scrutiny or outside review. Thus, if NEPA - or similar efforts to change the mission of agencies - is likely to succeed, it will require significant inputs of time and energy by the principal to provide the necessary political or legal pressure. It is an open question how often a principal will be committed to making this happen. ${ }^{148}$

145 This was one of the conclusions of CEQ's thorough study of the operation of NEPA. See CEQ, supra note 137, at ix, 11 ("Generally agency and private sector planning processes begin long before the NEPA process. . . NEPA is virtually ignored in formulating specific policies and often is skirted in developing programs."). Other commentators have reached similar conclusions. See ANDREws, supra note 133, at 158 (concluding that NEPA has had little success in changing underlying mission orientation of most federal agencies); MAZMANIAN \& NIENABER, supra note 133, at 45-46, 133, 181-82, 185-87 (noting that NEPA has changed orientation of the Corps toward development projects at the margins, but that agency as a whole is still primarily focused on large construction activities); L.K. Caldwell, Implementing NEPA: A Non-Technical Political Task, in ENvironmental Policy and NEPA: PAST, PRESENT, AND FUTURE, supra note 129, at 25, 42) (author, one of the framers of NEPA, stating that "[a] greater handicap to achieving NEPA objectives . . . has been a too frequent failure - inadvertent or deliberate - to integrate NEPA policy into agency planning and decision making"); Wichelman, supra note 142, at 294-95.

${ }^{146}$ See ANDREwS, supra note 133, at 69-73, 89, 154 (noting changes in projects run by the Corps usually resulted from external pressure, not from internal changes due to NEPA); $i d$. at 111-12,130,145-46 (arguing that less effective implementation of NEPA by Soil Conservation Service is in part due to reduced external pressure); id. at 73 (" $[\mathrm{R}]$ arely . . . did any . . . significant changes of existing projects result from internal re-evaluation by the Corps in the absence of some form of pressure from outside the federal government."); TAYLOR, supra note 130, at 232-33, 258 (stating that success of NEPA depended on outside pressure for agencies to implement it); see also LiRofF, supra note 143, at 134, 140 (noting this dynamic); MAZMANIAN \& NiENABER, supra note 133, at 2-3, 79, 133 (hypothesizing that NEPA had significant impact on the Corps because of outside pressure, and providing examples from case studies).

${ }^{147}$ See ANDRews, supra note 133 , at $142-43$ (noting role litigation played in forcing that Corps to implement NEPA); TAYLOR, supra note 130, at 268 (same).

${ }^{148}$ For a discussion of how it might be difficult for a principal consistently to expend the political capital necessary to force changes in mission or information development by agencies, see supra notes 34-35 and infra notes 187-197 and accompanying text.

External pressure as a result of NEPA's information disclosure may be countered by other outside forces that shield an agency's decision. For example, soon after the enactment of 
There is also another limitation to the role that NEPA or similar legal or institutional design tools can play. These tools are intended to change the mission of agencies by reducing hostility to innovation on secondary goals. However, if that change proceeds too far, then an agency might ultimately convert its mission into a new one, centered on what previously was the secondary goal. The result could very well be greatly reduced performance on the formerly dominant goals - an outcome that may be equally problematic, or even worse. For example, if NEPA is too successful, it could theoretically change all the agencies in the federal government into agencies whose primary mission is environmental performance, leaving us with potential overperformance in the area of environmental protection, at the expense of other socially valuable goals.

\section{Using "Inter-Agency Interactions" To Solve the Dilemma of Multiple-Goal Agencies}

But what if it is not the principal that is providing the pressure on the agency to change its focus? Instead of attempting to directly change the structure or culture of the multiple-goal agency, another option would be to attempt to use interactions among the various federal agencies to ensure minimal or adequate satisfaction of secondary goals. For example, Congress could use additional federal agencies to monitor and observe the activities of the multiple-goal agency to ensure that it is relatively faithful to the principal's instructions.

The "inter-agency interaction" solutions can be seen as dealing with the problem of agency missions. A monitoring agency can be chosen that has a different mission, and that different mission will not interfere with, and may even promote, innovation in measurement of the "secondary" goal. For instance, Congress might assign the job of determining minimal compliance with endangered species standards to a wildlife agency whose mission has historically focused on protecting wildlife. There is no conflicting mission (say, highway construction) to interfere with the wildlife agency's pursuit of new and better ways to measure performance with respect to endangered species protection. Therefore, better innovation is more likely than if the decision-making agency was solely in charge of innovation. ${ }^{149}$

NEPA, the Soil Conservation Service came under pressure from environmental groups for failing to comply fully with NEPA when constructing potentially damaging stream channelization projects. However, opposing pressure from individual members of Congress and local farm organizations protected the agency, at least in the political arena. See ANDREws, supra note 133 , at 127 .

${ }^{149}$ The monitoring agency model developed in this Part might also be seen as a creative way to split goals among multiple agencies, while leaving the ultimate task of coordinating among multiple goals in the original decision-making agency. See supra notes 124-125 and accompanying text (noting that splitting tasks among multiple agencies often ultimately will require such coordination). Of course, the coordination by the decision-making agency might still be skewed. But since a new agency is handling measurements and innovation, the skew might be reduced because measurements have been or will be improved. Alternatively, if the 
There are two main models of this type explored here. The first model is the monitoring agency as a "lobbyist," one that provides information and advice to the multiple-goal agent as to how that agent might adequately meet its secondary goals. The second model is the monitoring agency as a "regulator," one that uses legal sanctions and restrictions, either directly or indirectly, to ensure that the multiple-goal agent meets minimal standards in accomplishment of the secondary goals.

The "lobbyist" model has been well developed by DeShazo and Freeman, using the example of fish and wildlife agency comments on hydroelectric licensing proceedings by the Federal Energy Regulatory Commission ("FERC"). The "regulatory" model is explored through two examples. The first is OMB's cost-benefit review of proposed agency regulations. The second is FWS's implementation of the ESA's restrictions on federal agency actions that could jeopardize the existence of endangered species. The difference between the two examples depends on enforcement - OMB review is enforced only by sanctions from the White House, while the ESA relies on non-governmental actors to enforce through citizen suits, maximizing the effectiveness of the agency as regulator model.

In the end, the "lobbyist" and "regulator" models are not truly dichotomies, but instead are points on the opposite ends of a continuum. At one end, conclusions by a monitoring or reviewing agency about the adequacy of performance are purely hortatory. At the other, they are completely and automatically binding. The real world examples this Article relies upon are somewhat in between, with even the "lobbyist" model of FERC involving some legal consequences and the "regulatory" model of the ESA allowing for some loosened enforcement and slack.

\section{A. The Model of "Agency as Lobbyist"}

Near one end of the spectrum of using "inter-agency interactions" is the model of "agency as lobbyist." As described by DeShazo and Freeman, under the "agency as lobbyist" model, Congress specifically authorizes or instructs one agency to lobby the decision-making agency. ${ }^{150}$ The lobbying agency frequently represents a particular interest, either through statutory mandate, agency culture, or connections with particular private client groups. ${ }^{151}$ That interest, in turn, is one of several interests or goals that the decision-making agency is required to consider in making its decision. ${ }^{152}$

monitoring agency has some sort of veto power requiring minimal decision-making standards to be met, the principal might be seen as having created an ex ante decision structure that helps resolve the tradeoff between the conflicting goals in a way that is less skewed against the "secondary" goal than in the past.

${ }^{150}$ DeShazo \& Freeman, supra note 5, at 2221-22.

151 See id. at 2227-28. DeShazo and Freeman's study focuses on comments on FERC proceedings, but there are a wide range of other examples, such as EPA comments provided on NEPA documents produced by other agencies. See infra note 162 and accompanying text.

${ }^{152}$ See DeShazo \& Freeman, supra note 5, at 2222-27. 
Through its participation in the processes of the decision-making agency, the lobbying agency is able to increase the decision-making agency's consideration of that goal or interest, which it previously had systematically undervalued or ignored. ${ }^{153}$

DeShazo and Freeman develop this model based on empirical evidence drawn from a particular case study - FERC's approval or renewal of licenses for hydropower dam projects. While Congress had charged FERC with considering a wide range of factors in making these decisions, including environmental protection, FERC had historically prioritized only one goal - the quick approval or renewal of licenses for new or existing dam projects. ${ }^{154}$ The causes of this systematic bias are probably overdetermined - both agency culture within FERC, as well as the structure and composition of the relevant congressional committees that oversaw FERC, pushed FERC in this direction. ${ }^{155}$ In response, Congress passed a law that required FERC to more seriously consider comments about the environmental impacts of licensed dams from fish and wildlife agencies (both state and federal). ${ }^{156}$ DeShazo and Freeman show through statistical analysis that, after the passage of the statutory changes, FERC consistently imposed more environmental conditions on the approval or renewal of dam licenses, and that this is correlated with increased participation in FERC licensing programs by fish and wildlife agencies. ${ }^{157}$

The model identified by DeShazo and Freeman has been used in a wide range of situations beyond FERC licensing decisions. Under the regulations that implement NEPA, ${ }^{158}$ agencies that are producing an EIS are required to "obtain the comments of any Federal agency which has jurisdiction by law or special expertise with respect to any environmental impact or which is authorized to develop and enforce environmental standards." 159 Those agencies, in turn, have a duty to at least reply to the request for a comment, even if it is a statement that the agency has no comment. ${ }^{160}$ Given the sweeping application of NEPA to all agencies within the federal government, its imposition of a duty to consider environmental values in all agency decision making, and the possibility that federal agencies with other, pre-existing statutory mandates may ignore or shirk this duty to consider environmental values, the "lobbyist" role created by the regulations implementing NEPA makes sense. ${ }^{161}$ For instance, one of the more frequent commenters on

\footnotetext{
${ }^{153}$ See id. at $2222-27,2298-300$ (drawing broader implications from the FERC case study).

${ }^{154}$ See id. at 2235-52.

155 See id.

${ }^{156}$ See id. at 2258-60; see also Electric Consumers Protection Act of 1986, Pub. L. No. $99-495, \S 7,100$ Stat. $1243,1248-49$ (codified at 16 U.S.C. $\$ 823 \mathrm{a}$ (c) $(2000)$ ).

${ }^{157}$ See DeShazo \& Freeman, supra note 5, at 2275-80. DeShazo and Freeman explicitly exclude the potential impact of litigation from their analysis of how FERC decision making changed. See id. at 2282 n.262.

${ }_{158}$ The regulations implementing NEPA are promulgated by CEQ. See supra note 137.

15940 C.F.R. \& $1503.1(\mathrm{a})(1)(2007)$.

${ }^{160}$ Id. \& $\$ 1503.2$.

${ }^{161}$ See supra note 158 and accompanying text.
} 
NEPA documents under this provision is EPA, which, as an agency, has a primary commitment to environmental values that would not necessarily be shared by other federal agencies. ${ }^{162}$ Accordingly, EPA through this NEPA process plays a role similar to that of fish and wildlife agencies under the FERC system.

As noted above, the "agency as lobbyist" model can be seen as an effort to overcome the limits that the mission orientation of the primary decision-making agency might pose to innovation. The principal can assign an institutional role to a monitoring agency to comment on issues that relate to one of the secondary goals. To the extent that the monitoring agency either does not have any goals that would conflict with pursuit of that secondary goal or (perhaps even better) has a mission oriented around that secondary goal, it will not have any incentives to avoid innovation in the measurement of the secondary goal. For instance, in the example of the wildlife agencies that were providing comments on the impacts of FERC dam licenses on fish and wildlife, those agencies would not have any conflicts in developing better information about those impacts. Indeed, for such agencies the goals might be complementary instead of substitute - developing better information about the impacts of the dam licenses might well help them pursue other goals with which they are directly tasked. In addition, Congress might provide direct incentives (through oversight, budgets, etc.) to encourage the monitoring agencies to develop better information.

This solution has similarities with NEPA and related efforts by the principal to change the mission of decision-making agencies. But this solution might be less costly and more effective because instead of trying to alter an agency whose mission will naturally resist change, Congress can rely on another organization whose culture is consonant with promotion of the secondary goals in question.

However, the "agency as lobbyist" model has its weaknesses. Most importantly, the decision-making agency that is receiving the information and advice can simply choose to ignore it. ${ }^{163}$ At least in the idealized situation of the lobbyist, there will be minimal consequences for such a choice, unless the principal decides to use the information to penalize the decisionmaking agency. ${ }^{164}$ DeShazo and Freeman's analysis provides strong evi-

${ }^{162} \mathrm{EPA}$ is statutorily required to comment on "the environmental impact of any matter relating to duties and responsibilities" of EPA when an EIS is filed. 42 U.S.C. $\$ 7609$ (a) (2000).

${ }^{163}$ An agency may not in fact ignore the advice by the lobbying agency, as the data compiled by DeShazo and Freeman indicate in the case of FERC. See supra notes 150-157 and accompanying text.

${ }^{164}$ Efforts by the principal to penalize the decision-making agency will necessarily require the principal to expend precious time and energy on enforcement - cutting against the very purpose of delegation. See infra notes 183-197 and accompanying text (discussing how enforcement of OMB cost-benefit analyses depended on enforcement by the President against recalcitrant agencies); supra notes 34-35 (noting general problems of enforcement by principal). The inter-agency lobbying model shares this weakness with intra-agency control models such as NEPA, where ongoing enforcement by the principal may be required to ensure a change in agency culture. 
dence that decision-making agencies may not "blow off" the lobbying agency - but nonetheless, as the stakes for the decision-making agency rise, one might question whether the effectiveness of this option could decrease.

Moreover, there are questions about the extent to which the "lobbying" agency will continue to do battle in the form of negative comments and statements. There is evidence that agencies can be reluctant to explicitly and directly criticize one another, at least where they do not have comparable expertise and where there may be high political costs to the criticism. ${ }^{165}$ Commenting agencies that believe that their comments have minimal benefits, but result in open political conflict with another federal agency, may conclude that the lobbying game is not worth the political costs.

\section{B. The Model of "Agency as Regulator"}

An alternative model is one in which the monitoring agency does not just provide advice and comments to the multiple-goal agency. Instead, the monitoring agency's conclusions as to the adequacy of the multiple-goal agency's achievement of secondary goals might actually have legal bite, resulting in legal constraints or penalties.

This model can be seen as attempting to address both of the "functional" approaches to the multiple-goal agency problem. Like the "agency as lobbyist," its purpose is to provide for innovation in measurement by another agency that does not have conflicting goals or missions. This model goes further by providing a legal constraint or penalty when the decisionmaking agency does not comply with the monitoring agency's conclusions as to whether minimum performance on the secondary goal has been achieved. In fact, it can be seen as an attempt by the principal both to split decision making about conflicting goals among multiple agencies and to develop a more balanced coordination system to allocate resources among those goals.

As discussed earlier, one of the problems with splitting agencies in order to separate conflicting goals is that coordination may often still be required among the split agencies and may itself be susceptible to being skewed. However, where the principal requires some sort of minimum standard to be met, then it has tried to address ex ante the coordination problem. Below the minimum level set by the monitoring agency, the secondary goal will trump the primary goal. Above the minimum level, the primary goal can proceed. In other words, with these types of systems, the principal itself has made the decision of how to trade off between the conflicting goals, albeit through a decision-making structure of minimum performance standards. And, as noted above, because the monitoring agency will often be

${ }^{165}$ See, e.g., TAYLOR, supra note 130, at 174-76 (noting EPA reluctance to make direct and harsh critiques of other agencies' EIS documents); Gilbert F. White, Environmental Impact Statements, 24 Prof. Geographer 302, 305 (1972) ("[W]ithin a few years after the Federal and State agencies became deeply involved in critical review of each other's [government water] projects they worked out accommodations that obscured or submerged the major points of difference among them."). 
chosen for its lack of conflicting goals and suitable mission, it will have an incentive to not only improve performance on the "secondary" goals, but also innovate in measuring those goals.

This Article looks at two examples of inter-agency monitoring: first, "direct" regulation by OMB of regulatory actions by agencies in the federal government to ensure the maximization of benefits over costs; second, "indirect" regulation by FWS of decisions by federal agencies to ensure the protection of endangered species. These examples were selected because they are emblematic of an important distinction in inter-agency regulation the nature of the enforcement mechanism. OMB review provides an example of inter-agency regulation where enforcement is limited to the Executive Branch itself, without the possibility of non-governmental parties intervening (at least officially or legally), while FWS consultation for endangered species adds the additional element of enforcement by non-governmental parties.

\section{Direct Regulation: The Office of Management and Budget and Cost-Benefit Analysis}

One high-profile example of inter-agency regulation is the OMB responsibility to screen new federal regulations to determine whether the benefits of those regulations exceed the costs. ${ }^{166}$ In developing regulatory tools to achieve their primary goals, various federal agencies arguably may turn a blind eye to the costs that those regulations might have on the economy or society as a whole. ${ }^{167}$ In other words, achieving efficiency can be a secondary goal that various regulatory agencies might shirk in attempting to achieve other primary goals - such as environmental protection. ${ }^{168}$ Since the early 1980s, Presidents have expressed their concern about the risk that

${ }^{166}$ See Exec. Order No. 12,291, 3 C.F.R. 127 (1982) (repealed 1993); Exec. Order No. 12,498, 3 C.F.R. 323 (1986) (repealed 1993); Exec. Order No. 12,866, 3 C.F.R. 638 (1993), reprinted as amended in 5 U.S.C. $\$ 601$ (2000); Exec. Order No. 13,258, 67 Fed. Reg. 9385 (Feb. 26, 2002).

${ }^{167}$ See Christopher C. DeMuth \& Douglas H. Ginsburg, White House Review of Agency Rulemaking, 99 HARV. L. REV. 1075, 1081 (1986) (arguing that government agencies will " 'spend' - through regulations that spend society's resources . . - 'too much" on achieving their goals). Others have questioned whether this dynamic really exists. See Nicholas Bagley \& Richard L. Revesz, OMB and the Centralized Review of Regulation (N.Y. Univ. Sch. of Law, Law \& Econ. Research Paper Series, Working Paper No. 05-16, 2005), available at http://papers.ssrn.com/sol3/papers.cfm?abstract_id=786486.

${ }_{168}$ Of course, it might be that achieving efficiency is not a goal that agencies such as EPA should achieve, and indeed, courts have interpreted a number of EPA's governing statutes to prohibit the consideration of cost. See, e.g., Whitman v. Am. Trucking Ass'ns, 531 U.S. 457, 465 (2001) (noting provision of Clean Air Act that prohibits EPA from considering implementation costs when setting air quality standards).

Some economists might argue that efficiency is a "primary" goal in the sense that society should seek to maximize benefits and minimize costs for all agency decisions. However, in the context of many federal agencies, efficiency is either not mentioned at all in the statute, or (as noted above) explicitly excluded as a consideration. Thus, in terms of practical implementation by agencies, it is fair to say that efficiency can be seen as a "secondary" goal. In other words, the concern here is the agency's perception of what its primary and secondary goals are. 
federal regulatory agencies will issue cost-ineffective regulations and have instructed those agencies to take efficiency into account in their decision making, where permitted by law. ${ }^{169}$

In order to enforce those instructions, Presidents beginning with President Reagan have created a systematic program of regulatory review, centered on the Office of Information and Regulatory Affairs ("OIRA") in OMB. Pursuant to a series of executive orders, a selection of all rules issued by federal agencies must be sent to OIRA for its review prior to distribution to the public. ${ }^{170}$ OIRA reviews the proposed rules to ensure that the benefits of the draft regulations justify their cost - and it can require the agency that is proposing the rules to respond to its comments. ${ }^{171}$

But OMB's power is more than just the power to provide comments, as in the "agency as lobbyist" model. Under Presidents Reagan and George H.W. Bush, OMB possessed effective power to veto rules that it considered unacceptable - often through providing repeated comments and delay. ${ }^{172}$ Agencies that sought to promulgate rules that OIRA considered unacceptable ran a high political risk of upsetting OMB as a whole - the agency that approves budget and personnel requests for all federal agencies - and the President himself, who had made OMB review a centerpiece of "regulatory reform" efforts. ${ }^{173}$ And while President Clinton issued a revised Executive

${ }^{169}$ See Exec. Order No. 12,291 § 2(b), 3 C.F.R. at 128 ("Regulatory action shall not be undertaken unless the potential benefits to society for the regulation outweigh the potential costs to society ... ."); Exec. Order No. 12,866 § 1(a), 3 C.F.R. at 639 ("In deciding whether and how to regulate, agencies should assess all costs and benefits of available regulatory alternatives .... Further, in choosing among alternative regulatory approaches, agencies should select those approaches that maximize net benefits ....”). Although this Article has generally been using Congress as the proxy for the single "principal" that delegates to a government agency, in this situation it is the President who is the principal, instructing agencies to take into account the goal of economic efficiency.

${ }^{170}$ See Exec. Order No. $12,291 \$ \$ 1-3,3$ C.F.R. at 127-30 (requiring all agencies to conduct Regulatory Impact Analysis for "major rules" that have significant economic impacts, to submit those analyses to OMB for review and comment, to include cost-benefit analysis for OMB review, and to wait for final OMB comments and respond to those comments before promulgating the rule); Exec. Order No. 12,866 $\$ 3,6,3$ C.F.R. at 641-42, 644-48 (setting forth similar requirements, although narrowing the scope of reviewable rules).

171 See Exec. Order No. 12,291 \& 3, 3 C.F.R. at 128-30; Exec. Order No. 12,866 § 6, 3 C.F.R. at $644-48$.

${ }_{172}$ See Harold H. Bruff, Presidential Management of Agency Rulemaking, 57 GEo. WASH. L. Rev. 533, 561-62 (1989) ("[T]he ultimate steps of appealing to the presidential level or issuing a rule over OMB's objections are rare."); Erik D. Olson, The Quiet Shift of Power: Office of Management \& Budget Supervision of Environmental Protection Agency Rulemaking Under Executive Order 12,291, 4 VA. J. NAT. Resources L. 1, 44-45 (1984) (stating that while agencies can and do successfully fight attempts by OMB to reject proposed rules, such efforts require substantial political capital by the agency); Robert V. Percival, Checks Without Balance: Executive Office Oversight of the Environmental Protection Agency, LAw \& CoNTEMP. ProBs., Autumn 1991, at 127, 150 ("In August 1983, OMB officials could not cite a single instance in which a rule disapproved by $\mathrm{OMB}$ had been promulgated by the agency. Three years later, OMB was able to cite only six instances .... [All six exceptions were the result of a court-ordered deadline or White House approval].").

${ }^{173}$ See Bruff, supra note 172, at 560-62 (noting that political appointees in agencies often are reluctant to cross White House that appointed them, and discussing OMB's institutional powers over agencies); Sidney A. Shapiro, Political Oversight and the Deterioration of Regu- 
Order that sharply reduced OMB's ability to kill rules with delays, he also explicitly required either OMB approval of the rule for it to promulgate, or an appeal to the Vice President or President to override OMB objections. ${ }^{174}$

Thus, OMB provides an example of what this Article calls "direct interagency regulation." OMB monitors performance of agencies on a secondary goal - maximizing economic efficiency in the achievement of other goals such as environmental protection - and requires achievement of at least minimal performance on that goal before it would approve the issuance of a rule. ${ }^{175}$

There is little question that OMB review had an impact on federal agency performance in the 1980s and 1990s - particularly at EPA, which bore the brunt of OMB review under Presidents Reagan and George H.W. Bush. Numerous rules were postponed or altered in major ways as a result of OMB review. ${ }^{176}$ Regulatory agencies began developing their own inhouse capacity to do cost-benefit and regulatory analyses, both to be able to respond to $\mathrm{OMB}$ comments and to better justify and draft their regulations in

latory Policy, 46 ADMIN. L. REv. 1, 11 (1994) (stating that agencies rarely defied OMB because "few administrators were willing to engage in open defiance of the White House" and risk "OMB retaliation" through "slowing . . . review of other regulations, refusing to clear congressional testimony, and reducing the agency's budget requests to be submitted to Congress"); William F. West, The Institutionalization of Regulatory Review: Organizational Stability and Responsive Competence at OIRA, 35 Presidential Stud. Q. 76, 80 (2005) (noting that the drafters of President Reagan's executive order believed that agencies would comply with OMB comments because "agencies would hesitate to ignore suggestions from an organization that scrutinized their budgets and that enjoyed such close proximity to the president"). An anecdote reported in a congressional hearing in the 1980s recounted that a top EPA official, after EPA had promulgated a rule over OMB objections, received a phone call from an OMB official "informing him that "there was a price to pay for doing what we had done, and that we hadn't begun to pay." Percival, supra note 172, at 151 (quoting EPA: Investigation of Superfund and Agency Abuses (Part 3): Hearings Before the Subcomm. on Oversight \& Investigations of the H. Comm. on Energy \& Commerce, 98th Cong. 7-8 (1983)).

${ }_{174}$ See Exec. Order No. 12,866 \& 6(b)(2), 3 C.F.R. at 646-47 (time periods for OMB review); id. $\$ 8$ (requirement of OMB approval for publication of rules). President George W. Bush adopted the Clinton Executive Order with only minor changes. See Exec. Order No. 13,258, 67 Fed. Reg. 9385 (Feb. 26, 2002).

${ }^{175}$ There are observers who have argued that OMB in the Reagan and George H.W. Bush Administrations was in fact interested in deregulation for its own sake, rather than maximizing the economic efficiency of government regulation. For a trenchant critique of OMB review arguing that it is biased towards deregulation rather than efficiency, see Bagley \& Revesz, supra note 167, at 9-13; see also Olson, supra note 172, at 41,52-53 (critiquing Reagan-era OMB review for relying on industry sources, ignoring benefits of regulation, and focusing on eliminating regulation rather than making regulation more efficient); Douglas M. Costle, Environmental Regulation and Regulatory Reform, 57 WASH. L. REv. 409, 411, 417-23 (1982); Thomas O. McGarity, Reinventing Rationality: The Role of Regulatory analysis in THE Federal Bureaucracy 61 (1991) (making same point).

${ }^{176}$ See, e.g., Percival, supra note 172 , at 157 (providing data showing significant delays for OMB review of regulations, particularly for EPA). Despite these numbers, some observers have argued that OMB's impact in improving regulatory efficiency has been relatively limited. See E. Donald Elliott, TQM-ing OMB: Or Why Regulatory Review Under Executive Order 12,291 Works Poorly and What President Clinton Should Do About It, LAW \& ConTEMP. ProBs., Spring 1994, at 167, 176-77. 
anticipation of OMB review. ${ }^{177}$ An empirical study of OMB review of regulations under the Clinton administration indicated that almost one-half of all rules reviewed by OMB were changed, ${ }^{178}$ and for EPA rules issued between 1998 and 2000, almost ninety percent were changed. ${ }^{179}$

The benefit of this solution is that an outside agency, with a different mission and different expertise, is able to develop information about achievement of the secondary goal that the original agency may have ignored or dismissed. ${ }^{180}$ For instance, OMB has compiled a range of economists and policy analysts who are able to perform regulatory analysis that the rule-making agency may be unable or unwilling to perform. ${ }^{181}$

Alternatively, as noted above, the potential for OMB review can inspire improved analysis at the agency level that results in the production of more and better information. ${ }^{182}$ In this way, the OMB review process is similar to NEPA, in that it forced some changes in the mission orientation of decisionmaking agencies to require them to do a better job of innovating ways to develop information about the "secondary" goal of economic efficiency.

So is "direct inter-agency regulation" the most effective way to ensure that government agencies perform on all of their goals, not just their primary ones? Not necessarily. The OMB example is instructive not just in showing how this tool might work, but also its limitations.

For our purposes, the limitation that matters most is that, in order for direct inter-agency regulation to be effective, it requires significant political and managerial effort to apply to even a limited range of agency actions. While the scope of the Reagan and George H.W. Bush Executive Orders was quite sweeping on their face, in practice OMB focused its review on

177 See Bruff, supra note 172, at 559 (noting rise of "mini-OMBs" in federal agencies "to mimic OIRA review"); Olson, supra note 172, at 49-50 (stating that OMB review prompted development of more stringent internal review at EPA); Percival, supra note 172, at 161 ("Regulatory review has inspired EPA to increase its analytic capabilities."). Agencies also began to modify their proposals in anticipation of OMB review. See Oliver A. Houck, President $X$ and the New (Approved) Decisionmaking, 36 Am. U. L. Rev. 535, 544 (1987) (quoting OMB Director saying that "[a]gencies don't send over really loony things anymore"); Olson, supra note 172, at 45, 50 (noting EPA has altered content of proposed rules in anticipation of OMB review).

${ }^{178}$ See Steven Croley, White House Review of Agency Rulemaking: An Empirical Investigation, 70 U. CHI. L. Rev. 821, 849 (2003).

${ }^{179}$ See id. at 868.

180 See Thomas O. McGarity, Regulatory Analysis and Regulatory Reform, 65 Tex. L. REv. 1243, 1261 (1987) ("Another frequently expressed virtue of regulatory analysis is its capacity to bring information about the beneficial and detrimental aspects of regulatory alternatives to the attention of the decision maker in a coherent and systematic format.").

181 However, to the extent that OMB's resources are limited, it will have difficulty developing its own information to accurately evaluate agency proposals. See id. at 1276-84 (noting frequent occasions in which regulatory analysis has been hamstrung by limited resources and information); Mark Seidenfeld, A Big Picture Approach to Presidential Influence on Agency Policy-Making, 80 lowa L. REv. 1, 14-15 (1994).

${ }_{182}$ See MCGARITY, supra note 175 , at ch. 10 (providing numerous examples of attempts by regulatory agencies to develop cost-benefit and regulatory analysis techniques, with mixed success). 
only a fraction of the agencies and a fraction of those agencies' actions. ${ }^{183}$ Agency rules that eliminated regulations, as opposed to imposing regulations, were ordinarily exempt from stringent $O M B$ review. ${ }^{184}$ The vast majority of the regulations that ran into OMB resistance were issued by a handful of agencies, including EPA and the Occupational Safety and Health Administration. ${ }^{185}$ The Clinton Executive Order explicitly pared down the list of rules to be reviewed by OMB to a fraction of those covered under the Reagan Order - the number of rules actually reviewed by OIRA in 2000 fell to approximately a quarter of the number that had been reviewed in $1992 .{ }^{186}$

Thus, OMB review was most effective in limited circumstances because to be effective, it required the expenditure of limited political capital and energy by the principal, e.g., the President himself. As noted above, OMB under Presidents Reagan and George H.W. Bush did not have formal legal veto power over agency rule-making decisions, but it did have de facto veto power because defiance of OMB by an agency head risked serious political consequences from the White House. ${ }^{187}$ In other words, OMB was effective precisely because its task was made a high priority by the President himself. ${ }^{188}$ Indeed, OMB review of agency rulemaking has been used as a classic example of "presidential control of the federal bureaucracy" by various scholars. ${ }^{189}$

${ }^{183} \mathrm{See}$ Olson, supra note 172 , at 48 (stating that OMB review of "most non-major rules must be cursory" and in general OMB review is selective); Shapiro, supra note 173, at 8-9 (noting that much of what was reported to OMB in the 1980s and early 1990s "went unanalyzed, or underanalyzed, as a result of the small size of OIRA's staff'); West, supra note 173 , at 82 (" $[\mathrm{A}] \mathrm{s}$ a small organization, OIRA had never given more than cursory attention to most of the policies that federal agencies proposed each year.").

${ }^{184}$ See Olson, supra note 172 , at 54 ("In an OMB annual report on progress under [the Reagan Executive Order], OMB openly admitted that it exempts from review rules 'which relax or defer regulatory requirements ....'”). Of course, this might be because the true goal of the OMB review process was to deregulate, rather than to produce more cost-effective regulations. See supra note 175 and accompanying text.

${ }^{185}$ See Percival, supra note 172, at $128-55$ (noting how OMB review, and similar review under preceding Presidents, focused on environmental regulation); id. at 157, 163 (providing data showing that OMB review caused significantly more delays and changes for EPA rules than for other agencies); $i d$. at 180 (arguing that regulatory review is "inherently selective in nature"); see also Olson, supra note 173, at 41-42 (noting impact of OMB review on EPA rulemaking). This dynamic was not unique to the Reagan and George H.W. Bush Administrations - under President Clinton, EPA received a disproportionate share of OMB scrutiny. See Croley, supra note 178 , at $866-68,872-73$.

${ }^{186}$ See Croley, supra note 178 , at 847.

${ }^{187}$ See supra notes $172-174$ and accompanying text; see also Percival, supra note 172 , at 155 (stating that creation of vice-presidential task force on regulatory review "will undoubtedly increase EPA's hesitancy to appeal an OIRA veto").

${ }_{188}$ For a revealing quotation, see Houck, supra note 177, at 535 (quoting OMB official in 1986 as saying "[w]e are the president, that's what we are"); see also Olson, supra note 173, at 6 ("Contributing to OMB's power is its location in the Executive Office of the President. This vantage point gives it close ties to the White House, and substantial political clout.").

${ }^{189}$ See, e.g., Bruff, supra note 172, at 552 ("OMB is the President's principal institutional means for supervising the federal bureaucracy."); DeMuth \& Ginsburg, supra note 167, at 1075; Robert V. Percival, Presidential Management of the Administrative State: The Not-SoUnitary Executive, 51 Duke L.J. 963 (2001); Peter M. Shane, Political Accountability in a 
The limits to the effectiveness of direct inter-agency regulation are shown by a range of counter-examples. First, OMB review under President Clinton was a much lower priority - and accordingly, OMB review under President Clinton was less intrusive than it had been under Presidents Reagan and George H.W. Bush. ${ }^{190}$

Second, other White House agencies besides OMB have been tasked with attempting to achieve compliance on a range of secondary goals by federal agencies, but have had far less impact, precisely because their activities have not been a priority for the President. For instance, the Council on Environmental Quality ("CEQ") was created by NEPA not only to supervise agency compliance with the EIS requirements, but also to generally achieve higher levels of environmental performance throughout the federal government. ${ }^{191}$ But outside its duties of issuing regulations interpreting NEPA's EIS requirements and producing annual reports, CEQ has had little impact on environmental performance in the federal government, certainly nothing comparable to the impact that OMB has achieved. ${ }^{192}$

Third, there are a range of federal agencies outside the White House that have been tasked with imposing and enforcing mandatory requirements on other federal agencies. Their experiences have been mixed at best. For instance, EPA had great difficulty requiring the Tennessee Valley Authority ("TVA"), another federal agency, to meet clean air and water standards required by law. ${ }^{193}$ In general, the political science literature has concluded that it is very difficult for one government agency to consistently regulate and control another directly. ${ }^{194}$

Why does direct inter-agency regulation require so much political capital and energy? Large bureaucracies are not likely to voluntarily give up their autonomy to another government agency, particularly when giving up that autonomy would compromise the agency's achievement of its primary

System of Checks and Balances: The Case of Presidential Review of Rulemaking, 48 ARK. L. Rev. 161, 174-92 (1995); Shapiro, supra note 173, at 1; Peter L. Strauss \& Cass R. Sunstein, The Role of the President and OMB in Informal Rulemaking, 38 ADMIN. L. REv. 181 (1986).

${ }^{190}$ See Elena Kagan, Presidential Administration, 114 Harv. L. Rev. 2245, 2287 (2001) (noting that OMB review resulted in "fewer battles" under Clinton than under Reagan and George H.W. Bush); Percival, supra note 189, at 995-97; West, supra note 173, at 86 ("OIRA lost bargaining power in its dealings with agencies given that the Clinton administration was more regulation and bureaucracy friendly than its Republican predecessors.").

191 See Caldwell, supra note 145, at 25, 34, 37-40; Lynton K. Caldwell, Science AND the National Environmental Policy Act 60 (1982).

${ }_{192}$ See Caldwell, supra note 145, at 46 (noting CEQ's "failure to fulfill the expectations of the framers of NEPA").

${ }^{193}$ See Robert F. Durant, When Government Regulates Itself: EPA, TVA, and Pollution CONTROL IN THE 1970s, at 6 (1985) (studying this conflict, and noting "[t]ypically, officials avoid direct interagency confrontation"); id. at 78-80, 105-09, 135-36 (concluding that independent citizen suits against TVA were crucial to EPA's eventual success in forcing TVA's compliance with air pollution standards).

${ }^{194}$ See James Q. Wilson \& Patricia Rachal, Can the Government Regulate Itself?, PuB. INT., Winter 1977, at 4 ("In general, it is easier for a public agency to change the behavior of a private organization than of another public agency."); see also WILson, supra note 17, at 19394 (noting problems with inter-agency regulation in civil rights and environmental contexts). 
mission. ${ }^{195}$ Accordingly, some sort of mandatory enforcement mechanism is probably necessary for the regulation to be effective. But agencies do not generally sue each other in court, ${ }^{196}$ and absent litigation, the only alternative is to enlist higher-ups (either at the secretarial or presidential level) to attempt to enforce the regulatory mandate. ${ }^{197}$ Where higher-ups have made the achievement of the secondary goal a high priority - as with OMB review for economic efficiency in the Reagan and George H.W. Bush Administrations - then this model can be successful. But in the vast majority of cases, it is much less likely that the higher-level decision maker will choose to spend time and energy on the dispute. And even if intervention by the higher-level decision maker occurs, it is unclear that it will be resolved in favor of the regulatory agency. Thus, like NEPA and the "agency as lobbyist" model, OMB provides further examples of the limitations that principals in the public sector might face in enforcing secondary goals.

\section{Indirect Regulation: The Endangered Species Act}

Instead of having another federal agency make legal determinations about compliance with minimal standards for performance on secondary goals and enforcing those determinations, another approach is to allow parties besides a federal agency to enforce those standards. For instance, one option would be to allow a federal agency to reach a determination about

${ }^{195}$ See DuRANT, supra note 193, at 40 (noting how TVA resisted any interference in its activities from other federal agencies, including EPA); $i d$. at 45 (citing TVA lawyer's objection to loss of "independence" because of attempted EPA regulation); id. at 71 (observing how TVA turned to Congress and political allies to resist EPA regulation); Wilson \& Rachal, supra note 194, at 10 (noting importance of autonomy to government agencies, and their reliance on political allies elsewhere inside government to protect that autonomy). There is indeed evidence of this dynamic in the ESA context. See Brunson \& Kennedy, supra note 58, at 143, 151 (noting that Forest Service and BLM employees resent FWS jeopardy opinions required by ESA because they are seen as "unwarranted interference").

196 See Durant, supra note 193, at 120 (noting EPA's "well-known reluctance" to sue other federal agencies); $i d$. at 72 (discussing internal government policy prohibiting interagency lawsuits in 1970s and preventing EPA from litigating pollution violations against TVA); Sax \& Keiter, supra note 58, at 218-22 (stating that Park Service viewed litigation against Forest Service to prevent development that might harm Glacier National Park as undermining cooperative efforts and thus undesirable); Michael W. Steinberg, Can EPA Sue Other Federal Agencies?, 17 Ecology L.Q. 317, 325 (1990) (noting that Department of Justice in 1980s refused to allow EPA to sue other federal agencies for violations of environmental laws); Wilson \& Rachal, supra note 194, at 9 ("[I]t is rare in the extreme for one agency to sue another."). Various legal doctrines might also make it difficult for government agencies to sue each other. See Durant, supra note 193, at 133 (noting that TVA relied on sovereign immunity doctrine in 1970 s to resist EPA enforcement efforts). But see Confederated Tribes \& Bands of the Yakima Indian Nation v. FERC, 746 F.2d 466 (9th Cir. 1984) (providing example of federal wildlife agency suing FERC over dam licensing). For a discussion of the constitutional and policy issues raised by inter-agency litigation, concluding that no constitutional obstacles prevent inter-agency litigation see Steinberg, supra, at 317.

${ }^{197}$ See Wilson \& Rachal, supra note 194, at 8 ("Only the President has the authority, and it is unlikely that he will allow himself to be drawn into an interagency quarrel."); see also Kagan, supra note 190, at 2341 (arguing that "to achieve even technocratic goals, some real push from the political system is needed" to overcome bureaucratic inertia). 
whether a standard has been met for performance, and then allow any individual to file suit to enforce determinations that the standard has not been met. This Article refers to this model as "indirect inter-agency regulation."

Perhaps the best example of this model would be the ESA's Section 7 consultation process. The ESA provides for the designation of species as threatened or endangered. ${ }^{198}$ Species that are listed as threatened or endangered then generally receive protection from federal agency actions that would "jeopardize [their] continued existence" or result in "adverse modification of habitat" that is critical for the species. ${ }^{199}$ As interpreted by the Supreme Court case Tennessee Valley Authority v. Hill, ${ }^{200}$ these prohibitions are essentially absolute, with a cumbersome exemption system available that has only granted two waivers in almost thirty years. ${ }^{201}$

For the purposes of this Article, what is more interesting is the way in which section 7's prohibitions are implemented. Contrary to statutes such as NEPA, the agency that is proposing to take action that might harm an endangered species (the "action agency") does not do its own analysis of the potential harm. Instead, the action agency must enter into a consultation process with FWS to determine the potential impact of the action on the species. ${ }^{202}$ And it is FWS that prepares what is called a "biological opinion" that reaches the conclusion as to whether or not the agency action will ultimately cause jeopardy or adverse modification. ${ }^{203}$

Technically, the action agency might choose to disregard FWS's biological opinion concluding that jeopardy or adverse modification might exist and proceed with its action. ${ }^{204}$ However, in practice, such a course is rarely followed by a federal agency - for good reason. ${ }^{205}$ As the Supreme Court has pointed out, a federal agency that disregards a negative biological opinion is open to lawsuits by private parties using the ESA's citizen suit provision seeking an injunction against the federal action (which will almost

${ }^{198} 16$ U.S.C. $\S 1533(2000)$.

${ }^{199}$ Id. $\S 1536(\mathrm{a})(2)$.

200437 U.S. 153 (1978)

${ }^{201}$ See 16 U.S.C. \$ 1536(e) (establishing Endangered Species Committee, which can grant exemptions from section 7 prohibitions); Dale D. Goble \& Eric T. Freyfogle, Wildlife LAw 1312-13 (2002) (describing two exemptions granted by Committee, one of which was later overturned in court).

${ }^{202}$ See 16 U.S.C. $\$ 1536(\mathrm{a})-(\mathrm{c})$.

${ }^{203}$ Id. $\S 1536(\mathrm{~b})$.

${ }^{204}$ See Bennett v. Spear, 520 U.S. 154, 169 (1997) (noting that a biological opinion "theoretically serves an 'advisory function"').

${ }^{205}$ See id. ("In the government's experience, action agencies very rarely choose to engage in conduct that the Service has concluded is likely to jeopardize the continued existence of a listed species."); id. at 170 ("The Service itself is, to put it mildly, keenly aware of the virtually determinative effect of its biological opinions."). 
always be granted), ${ }^{206}$ and may also be liable for civil and criminal penalties for an illegal "take" of listed species. ${ }^{207}$

While the legal implications of Section 7 consultation are relatively clear, the actual impacts it has had in altering federal agency behavior are somewhat uncertain. The obvious intent of Congress in enacting section 7 was to make sure that federal agencies, caught up in pursuing their primary duties (such as building dams and highways or allowing mineral or timber development on the public lands) did not ignore the impacts their actions would have on rare and endangered species, and altered those actions so as to avoid seriously harming those species. ${ }^{208}$ If judged by the number of listed species that have actually gone extinct, then the Act has accomplished its goals relatively well - so far, of 1932 species listed since the passage of the Act in 1973, only 9 have gone extinct. ${ }^{209}$ On the other hand, the trends for many of the listed species (many of which were listed only in the past ten to fifteen years) are not so promising - as of 2004, the date of the most recent agency report, only six percent of listed species were improving, twenty-seven percent were stable, twenty-two percent were declining and forty-two percent were uncertain. Another two percent were "presumed extinct," although not officially yet delisted. ${ }^{210}$

Examination of the outcome of the process of Section 7 consultation leads to similarly mixed results. It is clear that action agencies have not been able to avoid the process of consultation - a study in 1992 of consultations in the prior five years found that over 73,000 consultations had occurred, of various levels of depth. ${ }^{211}$ However, of those, only a small fraction (approximately 130) led to findings of potential "jeopardy" for listed species - and of those, only an even smaller fraction (18) led to the

${ }^{206}$ See Tenn. Valley Auth. v. Hill, 437 U.S. 153 (1978) (granting injunction against nearly completed dam project that jeopardized a listed species of fish); 16 U.S.C. $\$ 1540(\mathrm{~g})(1)(\mathrm{A})$ (providing for citizen suits "to enjoin any person, including the United States . . . who is alleged to be in violation" of the ESA); Bennett, 520 U.S. at 163-65 (noting expansive scope of ESA's citizen suit provision).

${ }^{207}$ See Bennett, 520 U.S. at 169-70 (stating that "[a] Biological Opinion . . . alters the legal regime to which the action agency is subject" and noting that harm to listed species from agency action not in compliance with a biological opinion will result in "substantial civil and criminal penalties, including imprisonment").

${ }^{208}$ See Tenn. Valley Auth., 437 U.S. at 184-85.

${ }^{209}$ See Listed Species Summary (Boxscore), http://ecos.fws.gov/tess_public/pub/Boxscore.do (last visited Nov. 17, 2008) (on file with the Harvard Environmental Law Review) (providing total number of species listed under ESA); Delisted Species, http://ecos.fws.gov/ tess_public/pub/delistingReport.jsp (last visited Nov. 17, 2008) (on file with the Harvard Environmental Law Review) (enumerating species taken off of ESA lists for various reasons, including extinction).

${ }^{210}$ See U.S. Fish \& Wildlife Service, Report to Congress on the Recovery of Threatened and Endangered Species, Fiscal Years 2003-2004, at 21 (2004).

${ }^{211}$ See Oliver A. Houck, The Endangered Species Act and Its Implementation by the U.S. Departments of Interior and Commerce, 64 U. Colo. L. REv. 277, 318 (1993). As of 1992, 817 species were listed in the United States under the ESA. See Species Listings by Year, http://ecos.fws.gov/tess_public/pub/SpeciesCountByYear.do (last visited Nov. 17, 2008) (on file with the Harvard Environmental Law Review) (providing totals of species listed in each year). 
termination of proposed projects. ${ }^{212}$ Judging by these numbers, the ESA has had minimal impact on action agencies. And indeed, critiques of the Section 7 consultation process have noted that, in general, Section 7 consultations tend to (a) understate the potentially negative impacts of federal agency actions; (b) narrowly define the federal action that is being considered (in order to understate those impacts); (c) overstate the condition of the listed species at issue in order to minimize the possibility that the negative impacts will result in "jeopardy"; and (d) require minimal changes to federal agency actions to avoid a "jeopardy" finding. ${ }^{213}$

But examination of a few of the most important cases where the ESA has conflicted with proposed agency actions reveals that the Act can make a significant difference. One example is the dam project at issue in the Supreme Court's Tennessee Valley Authority v. Hill case. ${ }^{214}$ In 1978, the Tellico Dam was "virtually completed" and "essentially ready for operation" 115 at a cost of more than $\$ 110$ million ${ }^{216}$ — when the Supreme Court decided the case. Both FWS and the Supreme Court stood firm, despite the heavy economic and political pressures brought to bear against them. FWS concluded that the dam would jeopardize the existence of an endangered species, and the Court concluded that given that finding, the plain language of the Act mandated that the dam could not be completed. ${ }^{217}$

The Tellico Dam is not unique. Another high profile ESA conflict under section 7 occurred on national forest lands in the Pacific Northwest, involving the northern spotted owl. Litigation from environmental groups first forced FWS to list the spotted owl under the Act, ${ }^{218}$ then forced FWS to designate critical habitat for the owl, ${ }^{219}$ and then forced a court injunction prohibiting a wide range of logging projects on Forest Service and BLM lands in the Northwest that would harm the owl's habitat. ${ }^{220}$ In the end, the

${ }^{212}$ Houck, supra note 211 , at 318.

${ }^{213}$ See, e.g., Eric Biber, The Application of the Endangered Species Act to the Protection of Freshwater Mussels: A Case Study, 32 EnvTL. L. 91, 122-34 (2002); Daniel J. Rohlf, Jeopardy Under the Endangered Species Act: Playing A Game Protected Species Can't Win, 41 WASHBURN L.J. 114 (2001); Houck, supra note 211, at 315-28.

214437 U.S. 153 (1978).

${ }^{215}$ Id. at 157-58; see also id. at 198 (Powell, J., dissenting) (noting dam was eighty percent complete when lawsuit was filed).

${ }^{216}$ Id. at 200 n.6.

${ }^{217}$ See id. at 172, 194-95. The dam was later specifically exempted from the ESA by a congressional appropriations rider. See Goble \& FREYFogle, supra note 201, at 1179.

${ }_{218}$ N. Spotted Owl v. Hodel, 716 F. Supp. 479 (W.D. Wash. 1988); see also YAFFEE, supra note 2, at 107 . Field-level FWS biologists believed the owl should be listed, but were initially overridden by political appointees until the agency lost in court. See id. at 109, 111 14. Eventually, the agency's loss in court left it with no other credible alternative but to list the species. See id. at 116.

${ }^{219}$ N. Spotted Owl v. Lujan, 758 F. Supp. 621 (W.D. Wash. 1991).

${ }^{220}$ Seattle Audubon Soc'y v. Evans, 771 F. Supp. 1081 (W.D. Wash. 1991). Technically, this injunction issued because of the Forest Service's failure to develop management plans so that it could comply with its own regulations that require it to maintain "viable" populations of species in national forests, including the spotted owl. See id. at 1083 (quoting 36 C.F.R. $\S 219.19$ ). However, those violations were in part the result of the litigation that had forced the listing of the spotted owl. See id. at 1084-86. Moreover, the court relied heavily on the 
litigation led to a presidential-level summit of scientists, agency managers, environmentalists, and industry, and a fundamental reevaluation of how the Forest Service managed not just its lands in the Northwest, but across the country. ${ }^{221}$ While there are certainly still controversies about how the Forest Service manages its land, there can be no question that an agency that would even consider setting aside all of its roadless areas from any future commercial logging 222 is in many ways fundamentally different — and is balancing its multiple goals in a fundamentally different way. Many observers have directly connected the change in Forest Service culture and management in the past twenty years to the ESA battles over the spotted owl. ${ }^{223}$ Also supporting the conclusion that the spotted owl fights had a major impact on the Forest Service is the fact that there was a major decline in timber production by the Service on a national level shortly after the spotted owl cases, ${ }^{224}$ and

ESA listing of the species in granting the injunction. See id. at 1091. The importance of the ESA to the restrictions on Forest Service and BLM operations in the Northwest was shown by BLM's subsequent request to the Endangered Species Committee for an exemption covering forty-four timber sales in the Northwest. See Portland Audubon Soc'y v. Endangered Species Comm., 984 F.2d 1534 (9th Cir. 1993). Commentators also agreed that the ESA listing process was a pivotal factor in the spotted owl controversy. See YAFFEe, supra note 2, at 115 ("Perhaps nothing had more impact on the ... controversy as the decision by the FWS in April 1989 to propose that the owl be listed as a threatened species under the [ESA].").

${ }^{221}$ See Seattle Audubon Soc'y v. Lyons, 871 F. Supp. 1291, 1303-06 (W.D. Wash. 1994) (describing summit and detailed management plan produced for logging on federal lands in Northwest); YAFFEE, supra note 2, at 146 (noting that proposals in timber summit resulted in drastic reduction in timber production by Forest Service in Northwest).

${ }^{222}$ See Roadless Area Conservation Rule, 66 Fed. Reg. 3244, 3244 (Jan. 12, 2001) (to be codified at 36 C.F.R. pt. 294) (prohibiting all commercial logging in roadless areas of national forests). This regulation was later rescinded by the Bush Administration, a decision that was subsequently overturned in litigation. See California ex rel. Lockyer v. U.S. Dep't of Agric., 468 F. Supp. 2d 1140, 1149 (N.D. Cal. 2006).

${ }^{223}$ See, e.g., HIRT, supra note 57, at 273-74, 277, 286-87 (noting importance of spotted owl litigation for changing Forest Service performance, including an unprecedented revolt by the agency's supervisors against what they saw as unrealistic timber quotas); HAROLD K. Steen, The Chiefs Remember: The Forest Service 1952-2001, at 4-5, 111 (2004) (stating that spotted owl controversy forced fundamental changes for an agency that was "up against the wall"); YAFFE, supra note 2, at 324-25 (noting that spotted owl was central to change in values within the Forest Service); Cheever, supra note 57, at 603-04, 693 (arguing that litigation under ESA and other environmental laws forced fundamental changes to Forest Service operations); Elise S. Jones \& Paul Mohai, Is the Forest Service Keeping Up With the Times?: Interest Group and Forestry School Perceptions of Post-NFMA Change in the United States Forest Service, 23 PoL'Y STud. J. 351, 358-61, 363, 364 fig.4 (1995) (reporting that survey of interest groups and forestry school deans revealed perception that Forest Service became more environmentally aware in late 1980 s and early 1990 s, in significant part because of litigation, ESA, and efforts by FWS); Elise S. Jones \& Cameron P. Taylor, Litigating Agency Change: The Impact of the Courts and Administrative Appeals Process on the Forest Service, 23 POL'Y STUD. J. 310, 329-31 (1995) (concluding that litigation under NFMA and ESA related to spotted owl had significant impacts on Forest Service operations); Robert H. Nelson, Government as Theater: Toward a New Paradigm for the Public Lands, 65 U. CoLo. L. Rev. 335, 351-52 (1994) (stating that ESA "turned upside down" Forest Service management in 1990s).

${ }_{224}$ See Timothy J. Farnham \& Paul Mohai, National Forest Timber Management over the Past Decade: A Change in Emphasis for the Forest Service?, 23 PoL'Y STUD. J. 268, 270 (1995) (connecting large drop in national forest timber production during late 1980s to spotted owl litigation); Paul A. Sabatier, John Loomis \& Catherine McCarthy, Hierarchical Controls, Professional Norms, Local Constituencies, and Budget Maximization: An Analysis of U.S. For- 
the fact that the Service significantly increased its funding for wildlife reseach at the same time. ${ }^{225}$ Moreover, observers believe that the ESA continues to serve as a major constraint on Forest Service decision making outside the context of spotted owl habitat. 226

What the above examples make clear - particularly in contrast to the sometimes limp enforcement of the ESA by FWS in other contexts ${ }^{227}$ - is the importance of what this Article calls "indirect" as opposed to "direct" inter-agency regulation. The citizen suit provisions of the ESA allow the public at large to monitor the regulatory efforts by FWS and to challenge them in court when they appear inadequate. ${ }^{228}$ The result, as shown above by the outcome in both the Tellico Dam and spotted owl cases, is the possibility of much stricter and more effective inter-agency regulation. In essence, limitations in the ability of the principal to monitor the agency can be overcome by including citizens in the review and enforcement process, thus delegating the monitoring more broadly.

\section{The Advantages and Disadvantages of Inter-Agency Regulation}

Like the other solutions we have surveyed, inter-agency regulation has its costs and benefits. As the Tellico Dam and spotted owl examples show, it is probably the most effective tool at forcing a multiple-goal agency to consider secondary goals, particularly when it is "indirect," i.e., backed up by the possibility of citizen suits. Thus, for National Park Service officials who were interested in constraining the Forest Service management on neighbor-

est Service Planning Decisions, 39 AM. J. Pol. SCI. 204, 228 (1995) (arguing, based on employee survey and review of Forest Service planning documents, that timber production was much less important for Forest Service after 1980s, "because of the numerous court decisions mandating timber harvesting restrictions in order to protect fish and wildlife habitat").

${ }^{225}$ See Timothy J. Farnham, Forest Service Budget Requests and Appropriations: What Do Analyses of Trends Reveal?, 23 PoL'Y STuD. J. 253 (1995) (finding significant increases in Forest Service requests for, and congressional approval of, appropriations funding wildlife and recreation management in late $1980 \mathrm{~s}$ and early $1990 \mathrm{~s}$, concurrent with spotted owl litigation); Timothy J. Farnham, Cameron Proffitt Taylor \& Will Callaway, A Shift in Values: Non-Commodity Resource Management and the Forest Service, 23 PoL'Y STud. J. 281 (1995) (finding that Forest Service significantly increased outputs on non-commodity resources such as wildlife and recreation in late 1980 s and early 1990s).

${ }^{226}$ See Sax \& Keiter, supra note 58, at 214, 226 (noting importance of ESA in constraining Forest Service development activities near Glacier National Park); $i d$. at 260 (quoting one local reporter as saying "[t]he Forest Service only fears the jeopardy opinion [under the ESA] and prosecution under NEPA"); Joseph L. Sax \& Robert B. Keiter, The Realities of Regional Resource Management: Glacier National Park and Its Neighbors Revisited, 33 ECOLOGY L.Q. 233, 239, 241, 247-53, 275-76, 307 (2006) (following up on earlier study and noting importance of litigation under ESA and other environmental statutes in changing orientation of Forest Service near Glacier National Park).

${ }^{227}$ See, e.g., Sax \& Keiter, supra note 58, at 242 (discussing FWS caving to political pressure and allowing oil and gas development in a national forest despite potential harmful impacts to listed species).

${ }_{228}$ See 16 U.S.C. $\$ 1540(\mathrm{~g})(1)(\mathrm{B})-(\mathrm{C})(2000)$ (authorizing citizen suits against FWS to uphold various prohibitions or enforce mandatory duties under ESA); see also George Cameron Coggins \& Irma S. Russell, Beyond Shooting Snail Darters in Pork Barrels: Endangered Species and Land Use in America, 70 GEO. L.J. 1433, 1496-97 (1982). 
ing lands to protect resources such as the grizzly bear, there is "no more powerful tool than the ESA with which to obtain concessions from its neighbors." ${ }^{2} 29$

The strength of the ESA model is that it potentially combines both of the two major solutions to the multi-goal agency problem: splitting goals and changing agency missions. As discussed earlier, inter-agency regulation in general creates a decision structure that allows for the splitting of goals among various agencies to minimize conflicts while still allowing for some coordination (as designated ex ante by the principal). But the enforcement problems of the direct regulation model are addressed by allowing a wider range of parties to use their resources to force greater consideration of the secondary goal. With respect to agency missions, the ESA model gives the power and incentive for an agency whose mission might be more sympathetic to the secondary goal (here FWS and endangered species conservation) to innovate with respect to measurement of performance on that goal. In addition, the pressure that the ESA places on the decision-making agency might cause internal changes within that agency to make its mission more consistent with innovative measurement of the secondary goals as well - as can be seen by the changes in the Forest Service in response to the ESA.

Indeed, the role that outside pressure might play in causing the decision-making agency's mission to change is not limited to the ESA. Earlier, this Article alluded to the fact that NEPA has had more success when there has been outside pressure on the agency to change its mission, whether political or legal. ${ }^{230}$ NEPA as well can be enforced by private parties through judicial review (though less easily than the ESA) - and this tool arguably has led to much greater effectiveness than if enforcement had been limited solely to the political branches (Congress and the President), for the very same reasons as with the ESA. ${ }^{231}$

On the other hand, inter-agency regulation has its costs - particularly the transaction costs of consultation between agencies and litigation by citizens against the regulated agency. Perhaps more important, there is no guarantee that inter-agency regulation will lead to change - it will usually require monitoring and litigation by private parties, and dedicated implementation by the regulating agency. This last characteristic may be the fundamental problem with the ESA, because political pressures encourage FWS to implement the Act in a way that has led to marginal changes in most cases. ${ }^{232}$ Another possible cost, to the extent that the ESA is successful in changing the mission of the original decision-making agency, is that (as with

${ }^{229}$ Sax \& Keiter, supra note 58, at 226.

${ }^{230}$ See supra note 146 and accompanying text.

${ }^{231}$ See supra note 147 and accompanying text.

${ }^{232}$ However, even marginal changes can still be important. See, e.g., Biber, supra note 213, at 122-34 (noting importance of some Section 7 consultation outcomes for protecting vulnerable species). The episodic and sometimes capricious nature of judicial review of agency decision making is probably an important explanation for the variable success of the ESA as a regulatory technique. See, e.g., DeShazo \& Freeman, supra note 5, at 2246-48 (making these points in the context of FERC). 
NEPA) the ESA might do its job too well and convert agencies wholesale to the cause of endangered species protection at the expense of their formerly dominant mission. ${ }^{233}$

\section{The Continuum from Lobbyist to Regulator}

We have two potentially powerful tools for using other agencies to monitor and control the multiple-goal agency's performance on secondary tasks - a lobbying agency that provides information and advice to the decision-making agency, with the goal of shifting that agency's focus to a greater or lesser degree, and a regulating agency that not only provides information, but also determinations about compliance with legal standards that may either be enforced directly by the agency or indirectly through citizen suits.

It is important to keep in mind that the two models of lobbyist and regulator are not dichotomous, but part of a continuum. An agency lobbyist's comments, for instance, might carry especial weight because they could be the basis for a successful legal challenge to the multiple-goal agency's decision. At the same time, an agency regulator's early indications about its likely conclusion will often lead the multiple-goal agency to modify projects to avoid conflicts. For example, adverse comments by an agency about another agency's EIS documents - a form of lobbying - are more likely to lead a court to overturn the decision on judicial review. ${ }^{234}$

Nor do these two models have to be exclusive. Congress might well choose to use both when it is particularly concerned about a multiple-goal agency's performance. For instance, FERC is not just the recipient of lobbying via comments from other agencies that have intervened into licensing proceedings. It is also (as with every other federal agency) covered by the ESA, and given the nature of FERC's work, the ESA can have a very significant impact on its licensing decisions. ${ }^{235}$ Indeed, the two statutes might well interact, as comments from wildlife agencies about the impacts of FERC licensing decisions on wildlife (particularly endangered species) might be fodder for ESA challenges to FERC licensing approvals. ${ }^{236}$

Finally, the above discussion of the use of inter-agency lobbying or regulation as a tool to improve multiple-goal decision making has focused

${ }^{233}$ See infra notes $241-243$ and accompanying text.

${ }^{234}$ See, e.g., Michael C. Blumm \& Stephen R. Brown, Pluralism and the Environment: The Role of Comment Agencies in NEPA Litigation, 14 HARV. ENVTL. L. REv. 277 (1990); see also TAYLOR, supra note 130, at 268-69, 301 (noting same point, and arguing that inter-agency comments on EIS documents are a form of inter-agency regulation).

${ }^{235}$ Other federal agencies may be able to impose additional regulatory requirements on FERC in the licensing process. For instance, if a proposed dam will be within reserved federal public lands, FERC must include in the license any conditions that the federal agency managing those lands deems "necessary for the adequate protection and utilization" of such lands. 16 U.S.C. $\$ 797(\mathrm{e})(2000)$.

${ }^{236}$ DeShazo and Freeman also did not consider in their quantitative model the role that litigation might have played in changing FERC decision making, although they did discuss high-impact cases in the qualitative section of their piece. See DeShazo \& Freeman, supra note 5 , at 2282 n. 262 . 
on the use of government agencies as the lobbyists or regulators. But there is no necessary reason why government agencies need to be the primary parties to fill these roles. Indeed, private parties might fill those roles instead. For instance, one can see the "notice and comment" procedures for informal rulemaking under the Administrative Procedure $\mathrm{Act}^{237}$ as a route to allow "lobbying" by the public at large on agencies about to issue binding regulations to make sure that they do not ignore understudied issues. ${ }^{238}$ And more "corporatist" administrative systems, such as those in Europe and Japan, may include task forces, working groups, committees, "quangos," or even fully autonomous non-governmental organizations such as trade associations or trade unions that are given formal roles in informing or constraining government decision making in the same way as the inter-agency regulation discussed above..$^{239}$

\section{Conclusion: A Range of Solutions with Their Own Tradeoffs}

One point that the overview of solutions provided in this Article makes clear is that there are inevitable tradeoffs not just in the balancing of the different goals that multiple-goal agencies are pursuing, but also in the solutions that a principal might adopt to mitigate the problems of multiple-goal agencies. At one end, a principal might choose a more conciliatory, "insideout" process of attempting to persuade an agency to change its perspective (through the "agency as lobbyist" tool) or through internal cultural change. On the other end, a principal might choose to be far more aggressive in attempting to correct a bias on the part of the agency, through for example the use of external regulation of an agency backed up by the threat of litigation by outside parties as enforcement (the "indirect inter-agency regulation" tool following the model of the ESA).

The "softer" end of this range might be more gradualist, it might be less effective in dealing with entrenched perspectives and biases within an agency - as some of the critiques of NEPA point out. The "harder" end of this range might be much more effective in forcing dramatic shifts in agency outputs and perspectives - as some of the case studies from the ESA illustrate.

But on the other hand, there are reciprocal costs from the use of the "harder" tools, such as the energy and effort expended through the litigation process, in short, the transaction costs. These costs are visible in the significant amounts of litigation and administrative appeals that agencies such as

${ }^{237}$ See 5 U.S.C. $\$ 553($ b)-(c) (2000).

${ }^{238}$ See McCubbins et al., supra note 54, at 243 (making the general point that administrative procedural requirements can have substantive, political purposes and outcomes).

${ }^{239}$ See, e.g., Joseph L. Badaracco, JR., Loading THE Dice: A Five-Country Study of VINYl Chloride Regulation 57-112 (1985) (describing formal and informal roles for trade associations and unions in development of regulatory policy for occupational health and safety in Great Britain, West Germany, France, and Japan). 
the Forest Service encounter as they attempt to manage their operations on a day-to-day basis. ${ }^{240}$ They are also visible in critiques of how NEPA has resulted on occasion in a seemingly endless process of report-writing, litigation, and report-redrafting that may not contribute meaningfully to improving the quality of the information that an agency might need to make a final decision.

For example, one case study by Robert Kagan looked at the role that NEPA played in the expansion of the Port of Oakland in California. Several years of multiple environmental reviews, litigation, and internal agency debates still failed to resolve the questions of whether and in what way dredging in the San Francisco Bay could occur to allow the port expansion to go forward. ${ }^{241}$ One of the main obstacles that Kagan identified as responsible for increasing those litigation and transaction costs was the existence of multiple permitting agencies, each with its own single-minded goals, which interfered with a development agency's (here the Port of Oakland) own ability to trade off between the range of multiple goals implicated by a major port expansion. ${ }^{242}$ Because each of those agencies had veto power and a narrow focus, the primary goals of the development agency (such as the pursuit of increased efficiencies in port development) were subordinated, resulting in high costs in terms of delays, litigation, and report development. ${ }^{243}$

As this example demonstrates, the problem of multiple-goal agencies is not an easy one. It is inevitable that all agencies will have to trade off among the accomplishment of multiple goals and difficult decisions about prioritizations among those goals will have to be made. Indeed, that prioritization is necessary - not all of our agencies can all pursue the same goals, whether that be development, environmental protection, or open access to information.

On the other hand, the dysfunctions presented by multiple-goal agencies are real. Hard-to-measure goals that conflict with easy-to-measure goals will be systematically shortchanged in the decision-making process. History, agency culture, and political pressures may also "lock-in" certain goals as primary over other goals, even if that runs contrary to the instructions and mandates that have been given to the agency. If we fail to understand and appreciate these problems, we will be left with dysfunctional

${ }^{240}$ See OfFICE OF TECH. Assessment, supra note 68, at 96-101 (noting occasionally high levels of administrative appeals and litigation over Forest Service decisions).

${ }^{241}$ See Robert A. Kagan, Patterns of Port Development: Government, Intermodal Transportation, and Innovation in the United States, China, and Hong KONG 102-69 (1990).

${ }^{242}$ See id. at 124-26.

${ }^{243}$ See id. at 141-42 (characterizing maze of regulatory protections created by possibility of judicial review and inter-agency approvals as "the new feudalism," and arguing the "problem ... is the fragmented, unpredictable, inconsistent, often legalistic way in which legitimate values are balanced," resulting in the subjugation of "collectively beneficial projects ... to disproportionately costly demands and delays"); see also Robert A. Kagan, Adversarial Legalism and American Government, 10 J. Pol'y ANALYsis \& MgMt. 369 (1991) (discussing Port of Oakland case study and costs of "adversarial legalism"). 
policy outcomes, and the tools that we use to solve policy problems will fail or misfire.

But as this Article has outlined, not only can we often predict when dysfunctions will occur - there are also solutions that are available that have been widely explored and used by Congress, and that have already had some success in addressing the concerns presented by multiple-goal agencies. Certainly there are still questions about whether those solutions have been fully implemented, are fully effective, or have gone far enough. There may also be questions about whether they have gone too far. And those solutions themselves will present fundamental questions about how important the shirking of secondary goals by agencies really is in a particular context, and whether solving that problem will be worth the cost. But the typology of solutions developed in this Article does provide a toolkit that we can rely upon to help ensure that government agencies do not get so wrapped up in "tunnel vision" that they fail to fulfill the full range of important societal goals that they have been tasked with achieving.

Figure 1: Typology of Options To Address MultipleGoal Problems

\begin{tabular}{|c|c|c|}
\hline & \multicolumn{2}{|c|}{ "Institutional Structure" Strategies } \\
\hline "Functional" Solutions & $\begin{array}{c}\text { "Direct" Changes to } \\
\text { Decision-Making Agency }\end{array}$ & "Inter-Agency" Interaction \\
\hline Separate Conflicting Goals & Split Agencies & Agency as Regulator \\
\hline Improve Innovation & Change Agency Culture & $\begin{array}{c}\text { Agency as Lobbyist and } \\
\text { Agency as Regulator }\end{array}$ \\
\hline
\end{tabular}




\section{Figure 2: Advantages and Disadvantages of Options To Address the Problems of Multiple-Goal Agencies}

\begin{tabular}{|c|c|c|}
\hline Option & Advantages & Disadvantages \\
\hline $\begin{array}{l}\text { Intra-Agency Regulation: } \\
\text { Principal Makes Decisions } \\
\text { Itself (Wilderness Act) }\end{array}$ & $\begin{array}{l}\text { - Eliminates conflict between } \\
\text { goals for agent making deci- } \\
\text { sion }\end{array}$ & $\begin{array}{l}\text { - Costly to principal in time } \\
\text { and energy, undermines pur- } \\
\text { pose of delegation }\end{array}$ \\
\hline $\begin{array}{l}\text { Intra-Agency Regulation: } \\
\text { Split Agency (AEC) }\end{array}$ & $\begin{array}{l}\text { - Eliminates conflict between } \\
\text { goals for agent making deci- } \\
\text { sion }\end{array}$ & $\begin{array}{l}\text { - May still require coordina- } \\
\text { tion between agents for deci- } \\
\text { sion making, replicating } \\
\text { problem at different level } \\
\text { - May be infeasible for certain } \\
\text { types of decisions }\end{array}$ \\
\hline $\begin{array}{l}\text { Intra-Agency Regulation: } \\
\text { Directly Change Agency } \\
\text { Mission (NEPA) }\end{array}$ & $\begin{array}{l}\text { - Can eliminate obstacles to } \\
\text { innovation in goal measure- } \\
\text { ment }\end{array}$ & $\begin{array}{l}\text { - May require significant } \\
\text { enforcement efforts by prin- } \\
\text { cipal to ensure success } \\
\text { - May result in overemphasis } \\
\text { of secondary goals }\end{array}$ \\
\hline $\begin{array}{l}\text { Inter-Agency Regulation: } \\
\text { Agency as Lobbyist (FERC) }\end{array}$ & $\begin{array}{l}\text { - Outside agency without con- } \\
\text { flicting mission might inno- } \\
\text { vate better in goal } \\
\text { measurement } \\
\text { - Can provide information to } \\
\text { principal to evaluate per- } \\
\text { formance of decision-making } \\
\text { agency }\end{array}$ & $\begin{array}{l}\text { - Minimal enforcement absent } \\
\text { significant involvement of } \\
\text { principal, which is costly }\end{array}$ \\
\hline $\begin{array}{l}\text { Inter-Agency Regulation: } \\
\text { Agency as Direct Regulator } \\
\text { (OMB) }\end{array}$ & $\begin{array}{l}\text { - Outside agency without con- } \\
\text { flicting mission might inno- } \\
\text { vate better in goal } \\
\text { measurement } \\
\text { - Can provide information to } \\
\text { principal to evaluate per- } \\
\text { formance of decision-making } \\
\text { agency } \\
\text { - Stronger potential for } \\
\text { enforcement }\end{array}$ & $\begin{array}{l}\text { - Enforcement still may } \\
\text { depend on significant } \\
\text { involvement of principal, } \\
\text { which is costly } \\
\text { - Increased decision-making } \\
\text { cost because of expanded } \\
\text { review process } \\
\text { - May result in overemphasis } \\
\text { of secondary goals }\end{array}$ \\
\hline $\begin{array}{l}\text { Inter-Agency Regulation: } \\
\text { Agency as Indirect Regula- } \\
\text { tor (ESA) }\end{array}$ & $\begin{array}{l}\text { - Outside agency without con- } \\
\text { flicting mission might inno- } \\
\text { vate better in goal } \\
\text { measurement } \\
\text { - Can provide information to } \\
\text { principal to evaluate per- } \\
\text { formance of decision-making } \\
\text { agency } \\
\text { - Strongest potential for } \\
\text { enforcement, does not } \\
\text { depend on active involve- } \\
\text { ment of principal }\end{array}$ & $\begin{array}{l}\text { - Potentially high transaction } \\
\text { and litigation costs from } \\
\text { consultation process and citi- } \\
\text { zen suits } \\
\text { - May result in overemphasis } \\
\text { of secondary goals }\end{array}$ \\
\hline
\end{tabular}


